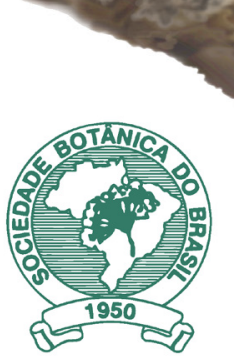

Acta Botanica Brasilica - 32(3): 329-348. July-September 2018 doi: 10.1590/0102-33062018abb0124
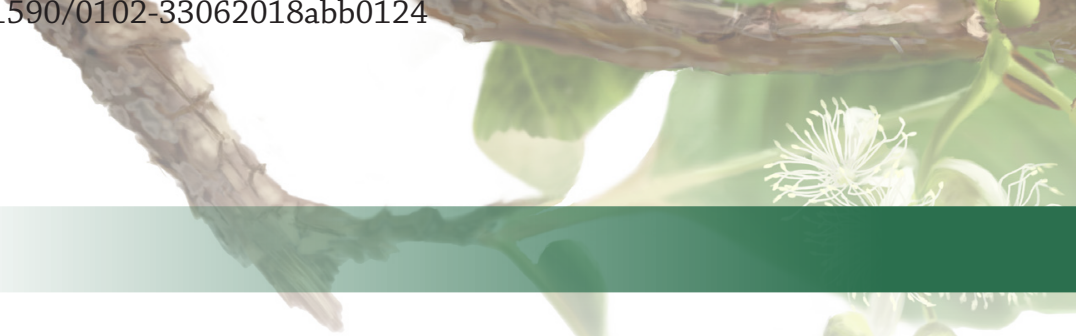

Review

\title{
Towards a unified terminology for angiosperm reproductive systems
}

\author{
João Custódio Fernandes Cardoso ${ }^{1 *}$ (1) Matheus Lacerda Viana² (D, Raphael Matias $^{3}$ (D, Marco Túlio Furtado ${ }^{3}$ (D), \\ Ana Paula de Souza Caetano ${ }^{1}$, , Hélder Consolaro ${ }^{4}$ (1) and Vinícius Lourenço Garcia de Brito ${ }^{5}$ (1)
}

Received: March 31, 2018

Accepted: July 2, 2018

\begin{abstract}
Angiosperms display an enormous diversity of forms, functions and strategies when it comes to reproduction. This multiplicity has been translated into several terminological concepts and contexts, which have facilitated further research. On the other hand, the use of terms that address the reproduction of flowering plants has been shown to be inconsistent in the literature, complicating communication among specialists. Key terms, such as "reproductive system", "mating system" and "sexual system", among others, have been frequently cited as synonyms, and even used in different circumstances. This review proposes to establish a consistent nomenclatural classification in the field of angiosperms reproductive biology in order to facilitate communication among researchers. Specific terms related to angiosperm reproduction are conceptualized and distributed into five general systems: four related to sexual reproduction (sexual, floral, incompatibility and mating systems); and one related to asexual reproduction (apomictic systems). Our proposal is not to establish a natural classification, but rather to provide a general overview of the main concepts that were grouped here in an artificial and functional manner. Our aim is to advance the field of reproductive biology of angiosperms with consistent and well-defined applications of relevant terminologies.
\end{abstract}

Keywords: apomictic systems, asexual reproduction, floral systems, flowering plants, incompatibility systems, mating systems, reproductive biology, sexual reproduction, sexual systems

\section{Introduction}

Angiosperms constitute a successful group of over 350,000 species that dominate terrestrial and some aquatic ecosystems worldwide, being one of the main model groups for studying several biological fundaments such as reproduction (Soltis et al. 2018). Charles Darwin himself (1877) was one of the pioneers to document the huge diversity of flowering plants reproductive strategies. Since then, several models and terminologies have been proposed through the decades in an attempt to explain the diversity and evolution of angiosperms' reproductive

1 Programa de Pós-Graduação em Ecologia e Conservação de Recursos Naturais, Universidade Federal de Uberlândia, 38400-902, Uberlândia, MG, Brazil

2 Programa de Pós-Graduação em Biologia Vegetal, Universidade Federal de Uberlândia, 38400-902, Uberlândia, MG, Brazil 3 Programa de Pós-Graduação em Botânica, Universidade de Brasília, 70919-970, Brasília, DF, Brazil

4 Departamento de Ciências Biológicas, Instituto de Biotecnologia, Universidade Federal de Goiás, 75704-020, Catalão, GO, Brazil

5 Instituto de Biologia, Universidade Federal de Uberlândia, 38400-902, Uberlândia, MG, Brazil

* Corresponding author: jcfclg@gmail.com 
systems (e.g. Yampolsky \& Yampolsky 1922; Lewis 1942; Fryxell 1957; Lloyd 1980; Bawa \& Beach 1981; Cruden \& Lloyd 1995; Richards 1997; Barrett 1998; 2002a; 2003; 2010a; b; Holsinger 2000; Charlesworth 2006; Renner 2014; Barrett \& Harder 2017).

However, the use of scientific terms regarding the reproductive biology of flowering plants has been inconsistent across literature. In fact, the variety of concepts and contexts in which these terms are applied has caused communication misunderstandings on this important area of knowledge. Key terms have been frequently cited as synonyms or applied in different circumstances. Moreover, such terms are used to describe more general phenomena, from those at species level, down to more specific, such as at the flower level.

Neal \& Anderson (2005) seminal work was one of the first to raise these terminological problems. They searched classical literature and found that "breeding system" and "mating system" were addressed to several different meanings. When searching specifically these terms as keywords, they corroborate their unclear usage. Finally, a questionnaire was sent to active research experts asking them to define such terms. These specialists used the terms in a wide range of circumstances, from specific to general contexts, and even considered them as synonyms. Despite they found a consensus in the usage of some terms (i.e. "breeding" and "mating systems"), this study still highlighted the necessity of standardization in the field of plant reproductive biology.

Several expert researchers recognize the nomenclatural misconception and the need of unification. Some of them attribute such inconsistency to the overlapping of terms between botany and other study areas (e.g. genetics, zoology, agriculture), which affect their application and understanding (Neal \& Anderson 2005). However, it is necessary for the active field of angiosperm reproductive biology to have its own terms and common usage. Seeking for a better communication among practitioners of the field, we distinguish and conceptualize the main terminologies in this review, following a nomenclatural classification based on literature itself, especially seminal studies. The general framework of our proposal is summarized in Fig. 1. We also present a glossary (List S1 in supplementary material) with etymology and short definitions of each term used here. In addition, we wrote an essay with a more detailed discussion for each concept, aiming to provide the state of art of terminologies for researches and students. In our proposal, the general reproductive systems of angiosperms were divided into five sections, which were distributed in sexual (1) and asexual reproduction (2). Within sexual reproduction, we present four classifications: sexual (1.1); floral (1.2); incompatibility (1.3) and mating systems (1.4). In asexual reproduction, we present the apomictic systems (2.1). As we have not considered vegetative reproduction, our review is restricted to terms referring to reproduction through seeds.

Sometimes, the different terms treated here are not clear cut, but rather distributed along a continuum. However, we insist in defining then to generate standardization and reliability across studies. It is important to highlight that, since several forms of reproduction by seeds have evolved independently in angiosperms, our proposal does not depict a natural and phylogenetically based classification. On the contrary, the different reproductive systems are grouped in an artificial and functional manner, according to the systematization discussed in this review. Furthermore, the terms used herein are not mutually exclusive, once a set of reproductive strategies may occur within the same

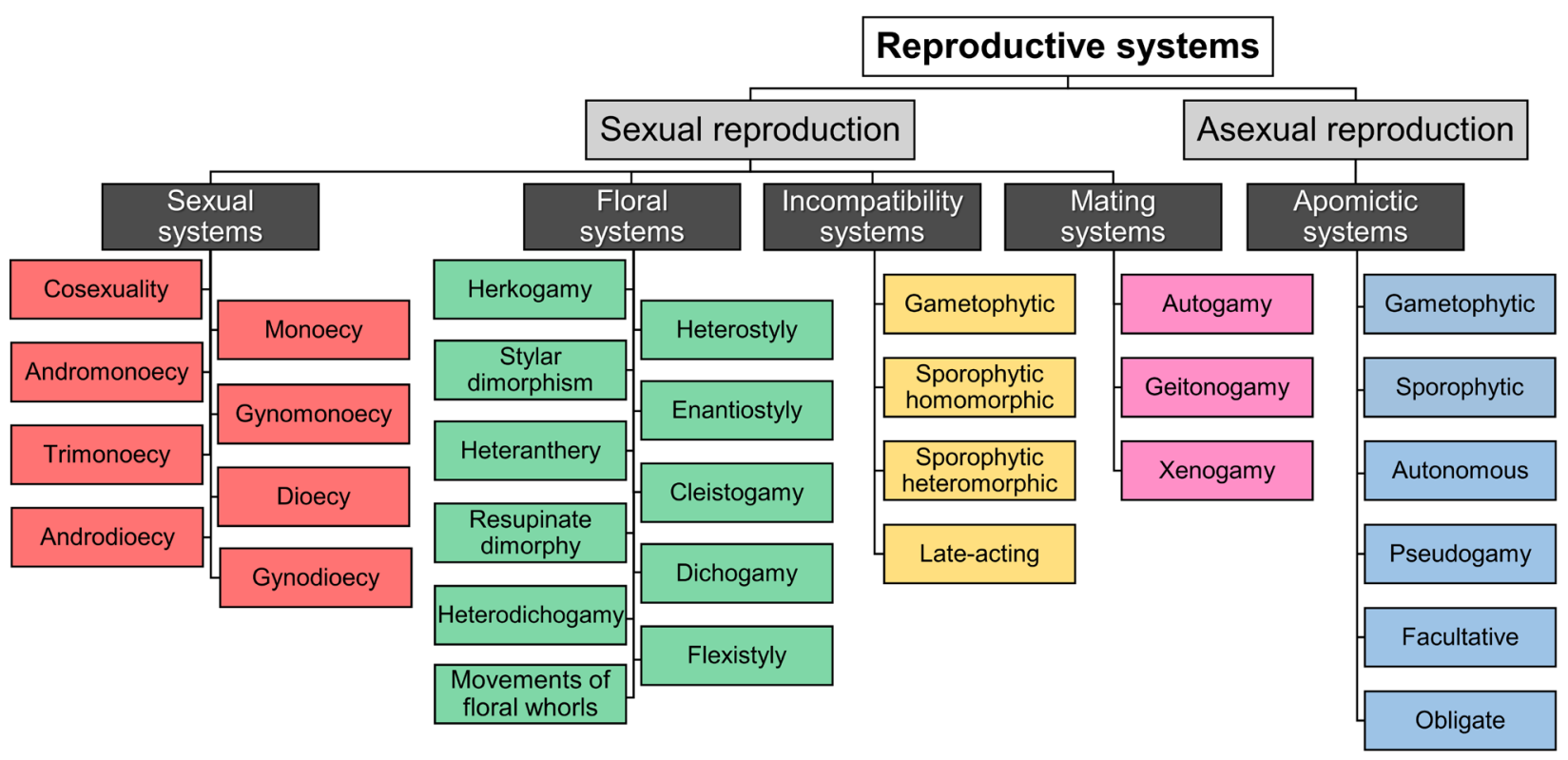

Figure 1. General framework of the different terminologies related to the reproductive system of angiosperms. 
species, individual or flower. Finally, in addition to general misconception, a given phenomenon may have several designations in literature, and the high number of synonyms may also hinder communication. For instance, flowers with the presence of both functional stamens and pistils are called bisexual flowers, but also androgynous, cosexual, hermaphrodite, monoclinous, or perfect flowers. Whenever existing, we summarize the most common synonyms for each term (within parenthesis), but along the manuscript, we use only one designation for each characteristic. To promote terminology standardization and common usage, we encourage our fellow researchers to follow the assigned terms rather than unusual synonyms.

\section{Reproductive systems (breeding systems)}

We suggest that "reproductive system" is a general term, comprising the phenomena and traits related to processes that occur between pollination and embryo formation. This includes, for instance, the set of sexual organs, their presence/absence, their arrangement in different levels (including the intrafloral, individual, population and species levels), the genetic relation between gametes, as well as incompatibility and asexual mechanisms. These characteristics allow plants to optimize their sexual and/or asexual reproductive process, adopting different strategies according to environmental, phylogenetic and genetic conditions. It is worth highlighting that the reproductive systems (focus of this review) are only part of the studies on the many aspects of floral biology, which also include, for instance, the pollination systems and floral development. We also suggest that the term "breeding system" is a synonym of "reproductive system". In this sense, reproductive systems encompass both sexual (1) and asexual reproduction (2) processes.

\section{(1) Sexual reproduction}

The term "sexual reproduction" may be extended to all mechanisms of genetic material exchange that lead to genetic variability (e.g. independent assortment of chromosomes and crossing over). In this section, however, we consider only mechanisms that somehow lead to gamete fusion and consequently fertilization. This includes gender expression, floral traits and their variations, as well as strategies that optimize or even avoid altogether the fusion of gametes.

\section{(1.1) Sexual systems}

Sexual systems include gender expression and its occurrence at different levels, such as intrafloral, individual, population, or species levels. It is based in the presence and distribution of fertile whorls within the flower. Flowers may be bisexual, with both stamens (male organs) and pistils (carpels) (female organs), or unisexual, with only male (staminate flower) or female (pistillate or carpellate flower) functional organs (Fig. 2). Further classifications are based on the distribution of these floral types within and among the individuals of a given population.

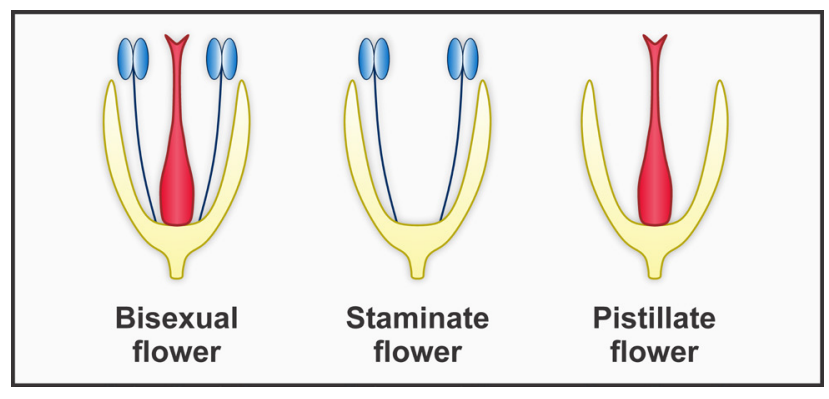

Figure 2. Flower-level sexual expression of angiosperms showing bisexual and unisexual (staminate and pistillate) flowers. Stamens (male organs) and pistils (female organs) are expressed respectively in blue and red shades.

\section{Cosexuality (bisexuality, hermaphroditism, monocliny)}

Sexual system in which individuals of a population present only bisexual flowers (androgynous, cosexual, hermaphrodite, monoclinous or perfect flowers), with functional stamens and pistils in the same flower (Fig. 3) (Silvertown \& Charlesworth 2001; Barrett \& Hough 2013). It is likely that cosexuality is an ancestral character state in angiosperms (Sauquet et al. 2017), being widespread in approximately $90 \%$ of species (Jong \& Klinkhamer 2005; Barrett \& Hough 2013). However, despite bisexual flowers have the advantage of producing male and female gametophytes within the same floral unit, this may entail some ecological and evolutionary conflicts. The main cost of cosexuality is self-pollen deposition on the stigma, which may lead to self-fertilization in selfcompatible plants and result in negative impacts to the population, such as inbreeding depression (Barrett 2002b; 2010a; Charlesworth \& Willis 2009). Another cosexuality disadvantage involves the physical interference between sexual functions (Lloyd \& Webb 1986; Webb \& Lloyd 1986; Barrett 2002b). The closer the male and female organs, the higher the chances of sexual interference. This may harm pollen removal, resulting in discounting of gametes. Furthermore, physical interference may also cause stigma clogging with self-pollen, creating a barrier preventing cross-pollen deposition and reducing fitness. These disadvantages may be minimized through different strategies that will be discussed throughout this review. 
Monoecy

Sexual system in which a population present only unisexual (diclinous) flowers and both staminate and pistillate flowers occur in the same individual (Fig. 3) (Barrett 2002a; Charlesworth 2006; Jong et al. 2008; Käfer et al. 2017). Monoecy is considered a derived condition in angiosperms (Mitchell \& Diggle 2005), with its occurrence varying from $5 \%$ in temperate (Lewis 1942) to $19 \%$ in some tropical regions (Ramirez \& Brito 1990). In most cases, the transition from cosexuality to monoecy has andromonoecy (see below) as an intermediate stage. This hypothesis, known as andromonoecy route, is based in the fact that the presence of staminate flowers would facilitate the production of strictly pistillate flowers from those bisexual (Jong et al. 2008). The alternative route, with gynomonoecy (see below) as a transition stage, is considered unlikely, since it requires an exorbitant fruit set by both bisexual and pistillate flowers (but see an exception in Asteraceae: Torices et al. 2011). There are still some cases in which monoecy reverts to cosexuality (Weiblen et al. 2000).

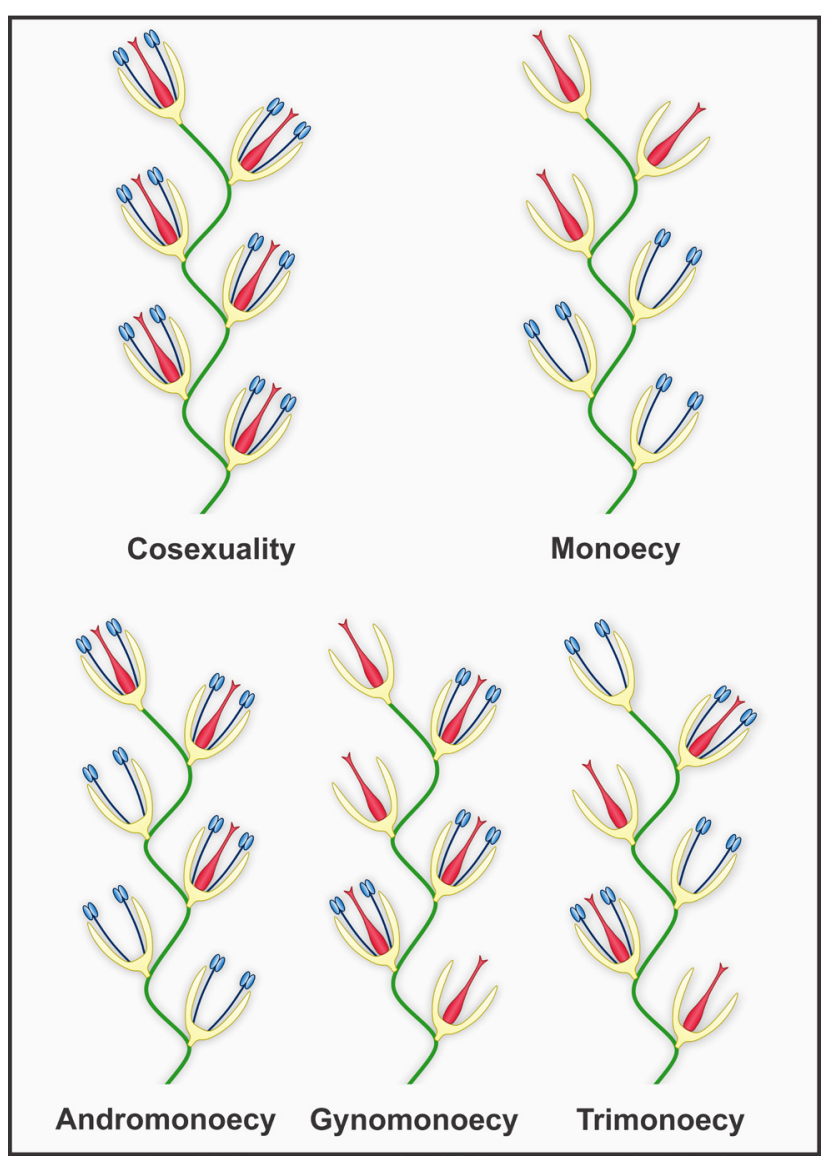

Figure 3. Population-level sexual expression of angiosperms showing the different types of individuals found on each system (including cosexuality, monoecy, andromonoecy, gynomonoecy, trimonoecy; see also Fig. 4). Stamens and pistils are expressed respectively in blue and red shades.
Although monoecy involves higher energy costs with the production of two floral types, this strategy allows the specialization in size, shape and positioning of male and female organs (Faegri \& Pijl 1979; Jong et al. 2008). This flexibility permits differential expression between genders in a variable environment (Freeman et al. 1980; 1981) and the establishment of an optimal balance between them in a more constant environment (Bertin 1982; Spalik 1991). In addition, monoecy reduces the intrafloral selfpollination, and minimizes geitonogamy (see topic 1.4) as well as sexual interference (Harder et al. 2000; Jong et al. 2008). Particularly, it is often associated with wind pollination and dichogamy, which reduces even more the chances of self-pollination (Crawley 1997).

\section{Andromonoecy}

Sexual system in which individuals of a population present bisexual and staminate flowers (Fig. 3), which may have a reduced, non-functional or even absent gynoecium (Jong et al. 2008). Andromonoecy evolved independently in several groups, being found in approximately $1.7 \%$ of angiosperms (Richards 1997). In general, the success of female function (formation of fruits and seeds) is a costly and limited process because it depends on resource availability (Janzen 1977; Lloyd 1980). On the other hand, for being smaller, pollen is relatively inexpensive, and can be produced in larger quantities. Moreover, male gametophytes can fertilize many different flowers, presenting a higher potential reproductive success than females. Based on this, the strategy of producing flowers with only male function (as in andromonoecy) may be evolutionary favored, once they may fertilize flowers with female function present, but do not involve costs related to production of functional pistils, fruits and seeds. In this sense, andromonoecy is particularly common in species with large and costly fruits, whose production is physiologically limited (Lloyd 1980).

\section{Gynomonoecy}

Sexual system in which individuals of a population present both bisexual and pistillate flowers (Fig. 3), with pollen sterility and a reduced or absent androecium (Jong et al. 2008). Gynomonoecy is distributed among 15 families, occurring in approximately $3 \%$ of angiosperm species (Yang \& Shuangquan 2006). Unlike andromonoecy, this mechanism is related to herbaceous species, with production of small and less costly fruits, as in Asteraceae (Richards 1997; Torices et al. 2011). It is argued that gynomonoecy tends to increase the female reproductive success and chances of originating descendants when compared to cosexuality (Yang \& Shuangquan 2006). However, other hypotheses have been postulated to explain the occurrence of gynomonoecy, such as the increase of cross-pollination, reduction in sexual interference, increase in pollinator 
attraction, defense against herbivores and flexible resource allocation (Yang \& Shuangquan 2006; Bertin et al. 2010; Zhang et al. 2012).

\section{Trimonoecy (polygamomonoecy)}

Trimonoecy is characterized by the presence of three floral types within the same individual in a population: bisexual, staminate and pistillate flowers (Fig. 3) (Cruden \& Lloyd 1995; Torices et al. 2011). This mechanism is rarer among angiosperms when compared to andromonoecy and gynomonoecy (Cruden \& Lloyd 1995), and have been proposed as a non-evolutionarily stable strategy in plants (Jong et al. 2008). According to the model of resource allocation, the production of bisexual flowers in a unisexual individual would lead to an abrupt decay of fitness (Jong et al. 2008). However, the route involving trimonoecy via gynomonoecy is parsimonious in Asteraceae (Torices et al. 2011). Once the sexual segregation within a capitulum is common in the family, the competition among developing fruits for resources may have favored the evolution of staminate or pistillate flowers in the group.

Dioecy

In this sexual system, entire individuals are unisexual, which means staminate and pistillate flowers are arranged in different plants of a population (Fig. 4) (Barrett 2002a; 2010b; Charlesworth 2006; Barrett \& Hough 2013; Käfer et al. 2017). Some species may still present subdioecy, so that unisexual individuals coexist with individuals presenting staminate and pistillate flowers (Charlesworth 2006; Munné-Bosch 2015).

Dioecy is less common when compared to cosexuality, occurring in about $7 \%$ of flowering plants (Renner \& Ricklefs 1995; Barrett 2010b). Nevertheless, this sexual system has a wide distribution, and has been observed in approximately half of angiosperms families (Heilbuth 2000) and evolved independently at least 100 times (Charlesworth 2002). Due to its lower frequency, some phylogenetic and theoretical models consider dioecy as an evolutionary dead end, because dioecious populations present reduced success and higher extinction rates than those cosexuals (e.g. Heilbuth 2000). However, other evidences suggest that dioecy is not rare because it promotes low fitness, but possibly because it is easily reverted to cosexuality, according to genetic and ecological conditions of the population (Käfer et al. 2017).

This sexual system may be genetically determined, involving sex chromosomes similarly to animals (Charlesworth 2002; 2013; 2015; Barrett \& Hough 2013; Käfer et al. 2017), and occurs in economically important species such as date palm, kiwi, and strawberry (Charlesworth 2013; 2015). On the other hand, dioecy may also be environmentally induced (Charlesworth 2006; 2013;
2015), in which less favorable environmental conditions usually determine male gender expression, while female expression develops under more appropriate conditions (Charlesworth 2006; e.g. Zimmerman 1991).

In order to reproduce sexually, dioecious populations are mandatorily dependent on pollen flow between male and female plants. Considering this, dioecy is hypothesized as a strategy that prevents self- and promotes cross-pollination. Furthermore, the division of labor and resource allocation between male and female components can be more efficient when the entire individual presents only a single sexual function (Charlesworth \& Charlesworth 1978; Bawa 1980; Barrett 2010b). On the other hand, dioecy also brings some disadvantages. Female individuals have the risk of not receiving pollen, which may culminate in fruit formation failures or even species extinction. This limitation may be related to the formation of androdioecious populations (see below), which present a higher pollen flow (Charlesworth 2006). Other long-term problem is related to the Y sex chromosome from the XY system. Since there is no genetic recombination between these two former chromosomes (as it occurs in autosomes), genes from the $\mathrm{Y}$ chromosome can accumulate deleterious mutations. As a result, this may lead to a low survival of male individuals, reducing the success of pollen carrying the $\mathrm{Y}$ chromosome (Charlesworth \& Charlesworth 2000; Charlesworth 2006).

In dioecious populations, male and female individuals may present several sexual dimorphisms related to life history, morphology or physiology (Barrett \& Hough 2013; Munné-Bosch 2015). These dimorphisms, vegetative or reproductive, are commonly associated with differences in reproduction costs, frequently higher in female individuals, which must bear fruits and seeds. Female plants may present lower vegetative growth, delayed flowering and with reduced frequency and even higher mortality rates when compared to males. Thereby, such differences may reflect on differential frequencies and distributions, which may lead to occupancy of distinct niches and even spatial segregation between males and females (Barrett \& Hough 2013).

Finally, considering dioecy evolution, several pathways were proposed based on bisexual flowers, varying according to the studied group. The most common is the route via gynodioecy (see below), wherein mutations related to the sterility of the male organs lead to the origin of female mutants, which then invade cosexual populations. Afterwards, natural selection favors male function in cosexual individuals, so that male individuals arise, originating dioecious populations. In the monoecy route, disruptive selection occurs in sexual allocation, which may generate differences in the proportion between the gender expression in individuals. This leads to the specialization on male or female functions until unisexual plants appear in the population. The androdioecy (see below) route has also been proposed, although apparently occurring at a lower frequency (see Barrett 2002a; 2010b; Charlesworth 2006; Käfer et al. 
2017 to more details about evolutionary routes of dioecy). In addition, a pathway based on distyly has been documented in some families such as Boraginaceae, Menyanthaceae and Rubiaceae. In these cases, the specialization of floral morphs in distinct sexual functions occurs, in which the long-styled usually specializes in female function and the short-styled in the male, leading them to present separate genders over time (Barrett 2002a; Käfer et al. 2017).

\section{Androdioecy}

Androdioecy is the presence of individuals with bisexual flowers coexisting along with others that present only staminate flowers (Fig. 4), and it is related to mutations that cause female sterility (Barrett 2002a; Charlesworth 2006; Barrett \& Hough 2013; Käfer et al. 2017). The origin and spread of androdioecious species is rarer and occurs under more restricted conditions when compared to gynodioecious (see below). In fact, in most of the times, androdioecy did not evolve directly from cosexuality, but rather from dioecy (Charlesworth 1984; Wolf \& Takebayashi 2004).

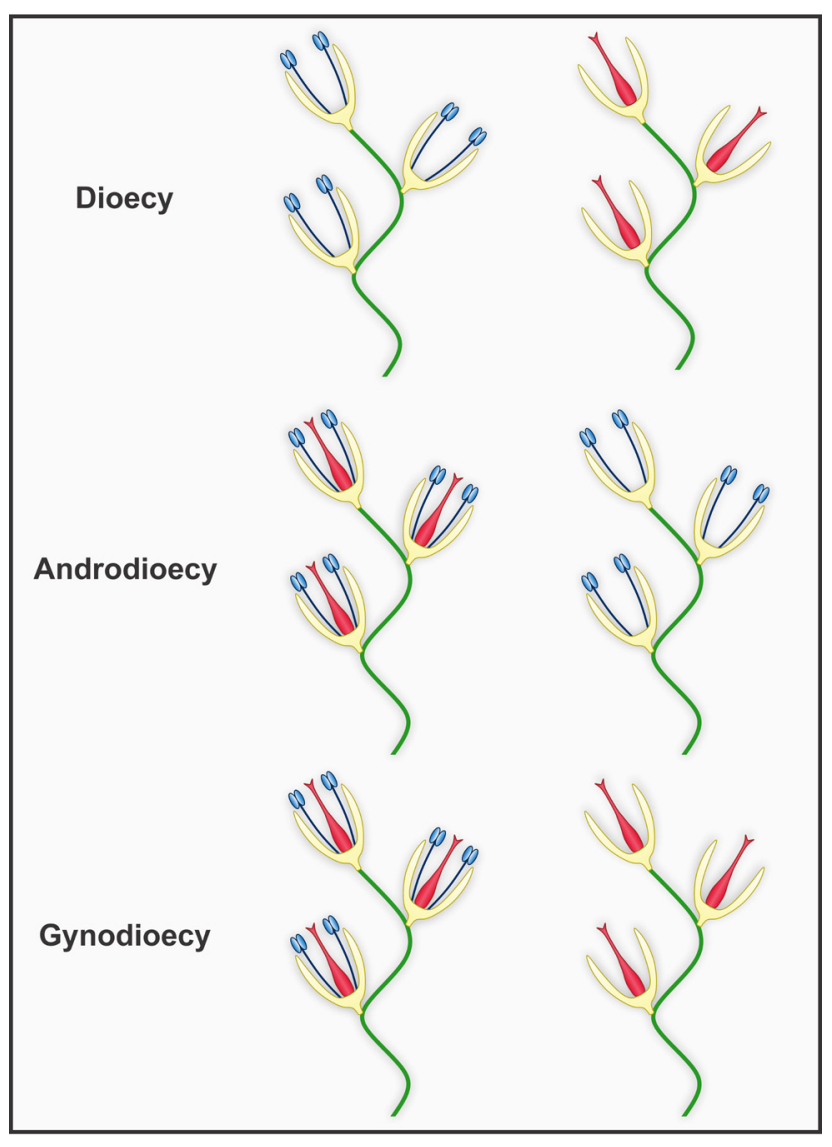

Figure 4. Population-level sexual expression of angiosperms showing the different types of individuals found on each system (including dioecy, androdioecy, gynodioecy; see also Fig. 3). Stamens and pistils are expressed respectively in blue and red shades.
The rarity of this sexual system occurs apparently because the pollen of the male individuals must compete with that of the cosexuals to fertilize ovules (Charlesworth \& Charlesworth 1978; Käfer et al. 2017). In this sense, mechanisms that reduce interference between sexes in cosexual individuals tend to maintain androdioecy, as is the case of the self-incompatibility system (SI) (see topic 1.4) (Saumitou-Laprade et al. 2010; Paer et al. 2015).

\section{Gynodioecy}

Gynodioecy refers to the presence of individuals with bisexual flowers coexisting along with others with only pistillate flowers (Fig. 4) (Barrett 2002a; Charlesworth 2006; Barrett \& Hough 2013; Käfer et al. 2017). Less than $1 \%$ of angiosperms present this sexual system (Godin \& Demyanova 2013). It arises due to mutations that cause sterility of the male organs in some individuals. The presence of unisexual plants in a population implies that they can reproduce in only one way (i.e. xenogamy; see topic 1.4), while the cosexual individuals also maintain reproduction via autogamy. Thus, for a population with mixed sexual systems to remain stable, unisexual individuals must present advantages. For instance, individuals with female-only function in a gynodioecious population must compensate the fact that they cannot transmit their genes through pollen grains (Lloyd 1975; Charlesworth 1981). Hence, for individuals with pistillate flowers to persist in the population, they must have greater female fitness, producing seeds in greater quality or quantity than the conspecific cosexuals (Charlesworth 2006). Still, female individuals are at risk of reduced fruit formation if pollinators have pollen as reward, presenting lower visitation.

Evolutionarily, the deleterious effects of self-pollination and inbreeding depression related to cosexuality over time are among the factors that contribute to the origin and maintenance of gynodioecy (Charlesworth \& Charlesworth 1978; Dornier \& Dufay 2013). Thus, the dependence of unisexual individuals on pollen flux ensures cross-pollination and genetic variability.

\section{(1.2) Floral systems}

Floral systems refer specifically to characteristics of bisexual flowers that optimize reproductive success, through mechanisms that promote self- or cross-pollination. Basically, the terms of the present systems that potentiate cross-pollination refer to variations in spatial and temporal presentation of the sexual organs in the flower that improve male and female functions. However, plants have also developed strategies that ensure their reproductive success by selfing, usually associated with limitation of pollinators. The different types of floral systems are summarized below according to morphology, temporal and movement-based mechanisms. 
Herkogamy

Herkogamy is the spatial separation anther-stigma along the vertical or horizontal plane within the same flower, functioning as a physical barrier that prevents both interference between sexual functions and self-pollination (Webb \& Lloyd 1986; Richards 1997; Barrett 2002b; Armbruster et al. 2014). Although herkogamy may also refer to the spatial separation of organs between flowers of the same individual (see Webb \& Lloyd 1986), herein, we adopt only the intrafloral concept of herkogamy. In addition, some authors consider herkogamy as a general term referring to any spatial separation of sexual functions in flower (e.g. Webb \& Lloyd 1986), including heterostyly, stylar dimorphism and enantiostyly (see below), mechanisms that are treated separately due to their peculiarities. In herkogamous flowers, pollinators touch part of their body only on a set of the sexual organs (anthers or stigmas). However, this same difference in the site of pollen deposition in the pollinator's body with the site of contact with the stigma may hinder effective pollen transfer between flowers (Webb \& Lloyd 1986; Armbruster et al. 2014). Horizontal herkogamy was detected, for instance, in Linaceae species (Ruiz-Martín 2018) but is mainly found in plants with enantiostyly (see below). In the vertical plane, flowers may display two forms of herkogamy: approach and reverse (Fig. 5).

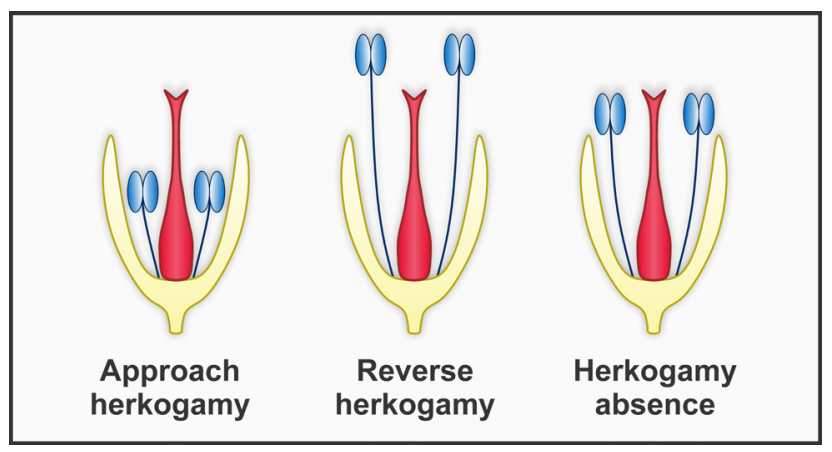

Figure 5. Different vertical herkogamy types (approach and reverse) and the absence of herkogamy. Stamens and pistils are expressed respectively in blue and red shades.

In approach herkogamy (1), stigma is positioned above the anthers, which may remain enclosed within the flower (Webb \& Lloyd 1986). Accordingly, pollinators first contact stigma and pollen grains are removed afterwards. Frequently, a second contact with stigma after pollen removal is unlikely, once receptive surface is located in the adaxial portion of stigma, preventing self-pollination. Approach herkogamy is the most common type among angiosperms (Webb \& Lloyd 1986). In reverse herkogamy (2), stigma is shorter and located below the anthers (Webb \& Lloyd 1986). In this way, it is expected anthers to be contacted before stigma during visitation, possibly depositing self-pollen on the stigma. Thus, despite the sexual interference within the flower is reduced by spatial separation, this type of herkogamy may be less effective than the approach herkogamy to avoid self-pollination (Luo \& Widmer 2013). In this sense, reverse herkogamy is uncommon and appear to be more frequent in flowers with narrow tubular corollas pollinated by Lepidoptera (Webb \& Lloyd 1986). Some authors also consider a last type of herkogamy based on movements of floral parts that encourage crossing or selfing (movement herkogamy) (Webb \& Lloyd 1986; e.g. Xiao et al. 2017). However, we consider them separately in "movements of floral whorls" (see below).

\section{Herkogamy absence (non-herkogamy)}

In contrast to herkogamous flowers, genetic modifications that result in herkogamy loss (Fig. 5) are common and often cause spontaneous self-pollination within the same flower (Vallejo-Marín \& Barrett 2009). For instance, the presence of non-herkogamous flowers along with other herkogamy types within the same population directly interferes in the crossing rate within flower varieties (Luo \& Widmer 2013). The term homostyly was used by Darwin (1877) to describe flowers without herkogamy in species originally with heterostyly (see below). In this sense, it is recommended to use this term only for species that are phylogenetically related to heterostylous groups (Ganders 1979).

The degree of stigma-anther separation to define a flower as kerkogamous is not well stablished, which generates an empirical problem. Some studies suggest that herkogamy exists when any separation degree occurs between stigma and anther (Luo \& Widmer 2013). Other studies consider herkogamous only those flowers with at least $3 \mathrm{~mm}$ of stigma-anther separation for small flowers and at least 10 mm for large ones (see Ramírez 2005).

\section{Heterostyly}

Heterostyly occurs when populations present individuals with two (distyly) (Fig. 6) or three (tristyly) floral morphs, which reciprocally differ in the heights of anthers and stigmas within flowers (i.e. reciprocal herkogamy; Ganders 1979). Distyly is the most common type of heterostyly, found in 26 out of 28 heterostylous families (Naiki 2012). It is characterized by individuals presenting flowers with long styles and short stamens (long-styled or pin morph), and others with short styles and long stamens (short-styled or thrum morph) (Darwin 1877; Ganders 1979; Barrett 1992; Lloyd \& Webb 1992; Barrett \& Shore 2008). In tristyly, the rearrangement of sexual organs heights results in three floral morphs, denominated long-styled, short-styled and mid-styled. Long-styled morphs have flowers with long style and two sets of stamens, one of short and the other of intermediate length; short-styled morphs have flowers with short style and intermediate and long stamens; and 
mid-styled morphs have flowers with style intermediate in length and long and short stamens (Barrett 1992; Barrett et al. 2000; Costa et al. 2016). Tristyly is found in seven out of 28 families with heterostyly, with Pontederiaceae and Thymelaeaceae exclusively tristylous. The other five families are reported as presenting both distylous and tristylous species (Naiki 2012).

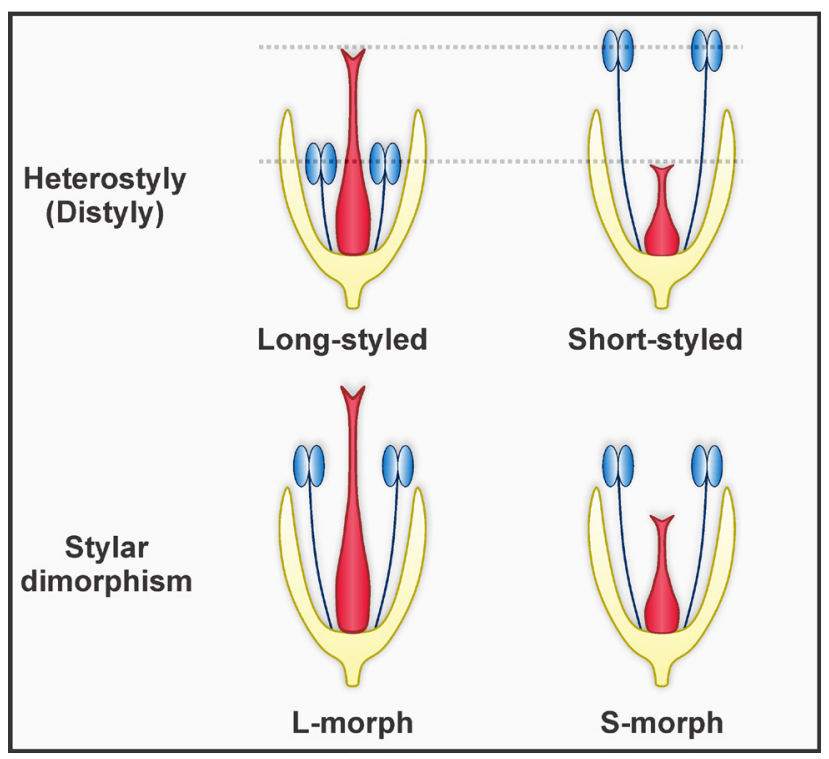

Figure 6. Heterostyly (specifically distyly) and stylar dimorphism displaying whorls arrangement of their respective floral morphs. Dashed lines indicate the direction of intermorph pollen flow. Stamens and pistils are expressed respectively in blue and red shades.

The typical reciprocal herkogamy found in heterostylous species (distylous and tristylous) is considered a trait that enhances gene flow by depositing pollen from each morph on specific parts of the pollinator's body, optimizing intermorph cross-pollination and consequently disassortative mating (Barrett et al. 2000; Barrett 2010a). In addition to the morphological arrangement, these species generally present a physiological system that favors cross-breeding, known as heteromorphic sporophytic self-incompatibility (see topic 1.3). In this case, through a pistil-pollen biochemical recognition, only the pollen from intermorph crosspollination develop completely and reach the ovules. Pollen tubes from self-pollination or intramorph cross-pollination have their growth interrupted before fertilization (Ganders 1979; Bawa \& Beach 1983; Barrett \& Shore 2008). Thus, heterostyly is a term settled within a floral system, but it usually encompasses incompatibility systems aspects.

In heterostyly, each individual has only one type of flower and, usually, populations display floral morphs occurring in the same proportion (isoplethy). However, some studies have demonstrated variations in this floral system, in which populations may not present such features typical of heterostyly. Accordingly, the frequency of floral morphs within populations may not be balanced (anisoplethy) and reciprocal herkogamy absent (Consolaro et al. 2011; Costa et al. 2016; Sá et al. 2016). Species evolutionarily related to heterostylous groups may also present populations with only one floral morphology, denominated monomorphic. Thus, depending on the floral type, populations may be long-styled, short-styled or mid-styled monomorphic (e.g. Consolaro et al. 2011). Another type of variation that can be found in heterostylous groups is homostyly (see "herkogamy absence"), characterized by the presence of flowers without herkogamy (Ganders 1979; Barrett \& Shore 2008).

\section{Stylar dimorphism (stigma-height dimorphism)}

Characterized by the presence of two morphs in the population differing only in style heights (Fig. 6) (Charlesworth \& Charlesworth 1979; Lloyd \& Webb 1992). The main difference when compared to heterostyly is the absence of reciprocal herkogamy, since in stylar dimorphism anthers are arranged in the same height in both morphs (Barrett et al. 2000; Ferrero et al. 2009; 2012). In stylar dimorphic populations, some individuals present flowers with stigmas positioned above anthers (L-morph), while others have stigmas below anthers (S-morph) (Barrett et al. 2000).

Stylar dimorphism has been poorly reported in angiosperms, being more commonly found in families with heterostylous species, such as Boraginaceae (Ferrero et al. 2012), Linaceae (Darwin 1877; Dulberger 1992), Primulaceae (Richards 1998) and Rubiaceae (Novo et al. 2018). Hence, stylar dimorphism may be an intermediary state related to the evolution of distyly. However, other families such as Ericaceae (O'Brien \& Calder 1989) and Liliaceae (Jernstedt 1982) present stylar dimorphic species without the occurrence of heterostyly.

\section{Enantiostyly}

This floral system is characterized by the lateral deflection of style (to the right or left) in relation to the central axis of the flower (Fig. 7) leading to horizontal herkogamy (Barrett 2002a; Jesson \& Barrett 2002a; 2003; Jesson et al. 2002; Barrett 2010a). This trait confers the appearance of mirror images to the two floral types (Barrett 2010a). Enantiostyly may occur in different levels (e.g. individual, inflorescence or flower), being classified as monomorphic or dimorphic (Barrett 2002a; 2010a; Jesson \& Barrett 2002a; 2003; Jesson et al. 2002). In monomorphic enantiostyly, both right- and left-styled floral types occur in the same individual. This may happen with flowers located in fixed or random positions within the inflorescence, or with the separation between inflorescences. On the other hand, dimorphic enantiostyly is characterized by entire individuals displaying the same floral type, right- or left- 
styled (e.g. Jesson \& Barrett 2002b). In this latter case, it was demonstrated that enantiostyly may be genetically controlled by a Mendelian locus with two alleles (Jesson \& Barrett 2002a; b). Furthermore, enantiostyly may be further classified as reciprocal, when anthers reciprocally follow style deflection (Fig. 7), or nonreciprocal, when anthers are centrally positioned and only style is deflected (Jesson \& Barrett 2003).

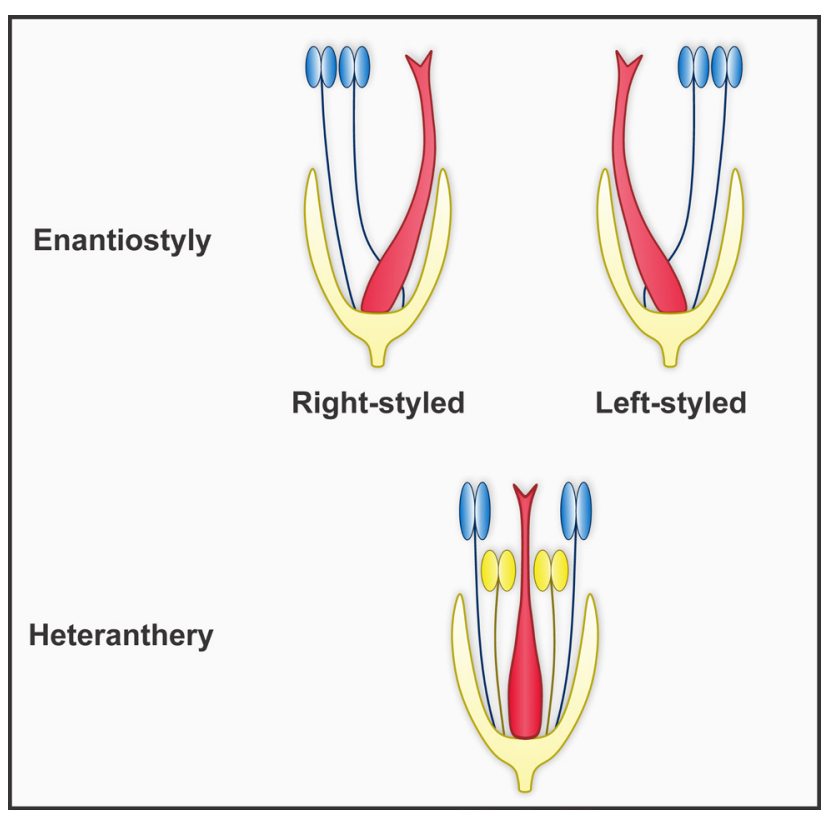

Figure 7. Reciprocal enantiostyly displaying whorls arrangement of the respective floral morphs. Stamens and pistils are expressed respectively in blue and red shades. Heteranthery showing stamens differentiation. Feeding and pollinating anthers are expressed respectively in yellow and blue shades while pistil is red.

Phylogenetic evidences indicate that monomorphic enantiostyly developed from ancestors with normal (non-deflected) reproductive organs, whereas dimorphic enantiostyly has derived from the monomorphic and is much rarer (Jesson et al. 2003). Monomorphic enantiostyly has arisen independently in at least 10 angiosperm families (in mono- and eudicots), while dimorphic has been found in only three monocot families (Barrett 2002a; Jesson et al. 2003). The most frequent adaptive explanation involving the evolution of enantiostyly proposes that this mechanism optimizes cross-pollination (Barrett et al. 2000; Barrett 2002a; 2010a; Jesson \& Barrett 2002a; 2003; Jesson et al. 2002; 2003). Since pollen deposition of right- and leftstyled morphs occurs in distinct sides of the pollinator, there is increased cross-pollination between these different floral types.

This process of differential deposition makes sense when dimorphic enantiostyly is considered. In monomorphic enantiostily, it is likely that geitonogamy occurs among different flowers of the same individual. Experimental evidence testing this hypothesis demonstrated that individuals without enantiostyly presented lower crossing rates when compared with both monomorphic and dimorphic enantiostylous individuals (see Jesson \& Barrett 2002a). This indicates that both enantiostyly types promote cross-fertilization. However, when these two are compared, monomorphic presents lower crossing rates, demonstrating that geitonogamy still occur in this group. Frequently, enantiostyly may be associated to heteranthery (see below), wherein reciprocal positioning of sexual organs generally involves the pollinating anthers, but not necessarily the feeding anthers (Vallejo-Marín et al. 2010).

\section{Heteranthery}

Heteranthery is characterized by the morphological, spatial and/or color differentiation among the stamens of the same flower (Fig. 7) (Buchmann 1983; Jesson \& Barrett 2003; Barrett 2010a; Vallejo-Marín et al. 2010). Heteranthery is widely distributed among angiosperms, occurring in more than 20 families from different orders, including Bignoniaceae, Commelinaceae, Fabaceae, Melastomataceae and Solanaceae (Jesson \& Barrett 2003; Vallejo-Marín et al. 2010).

Evolutionarily, heteranthery is considered an adaptive response of plants, saving resources for sexual reproduction. Since pollen is provided in different types of stamens, this promotes a division of labor between them. A group of stamens offers pollen to pollinators in the feeding anthers, while the other group provides pollen for reproduction in the pollinating anthers (Buchmann 1983; Vallejo-Marín et al. 2009; Barrett 2010a). Accordingly, it is suggested that the evolution of this trait is mainly influenced by the benefits of the partition of the pollen load for pollinator feeding and plant reproduction in flowers that present only pollen grains as resource (Luo et al. 2008; Vallejo-Marín et al. 2009). In fact, when depicting which traits are related to heteranthery, the most common are the presence of enantiostyly, poricidal anthers/buzz pollination, and the offer of only pollen as reward (Vallejo-Marín et al. 2010).

\section{Cleistogamy}

Refers to the presence of flowers that do not open, and which set fruits and seeds only via self-pollination (Lord 1981; Culley \& Klooster 2007). Cleistogamy may also be applied in a broader sense, to describe species that show closed (cleistogamous) and open flowers (chasmogamous) in the same population. The production of these two floral types provides cross-pollination and genetic variability (through chasmogamous flowers), but at the same time ensure fertilization and fruit formation via self-pollination (through cleistogamous flowers).

Fertilization in cleistogamous flowers occurs after the direct release of the pollen grains on the stigmatic surface 


\section{João Custódio Fernandes Cardoso, Matheus Lacerda Viana, Raphael Matias, Marco Túlio Furtado, Ana Paula de Souza Caetano, Hélder Consolaro and Vinícius Lourenço Garcia de Brito}

during floral bud stage, or even by pollen tube growth through anthers until stigma (Mayers \& Lord 1983). This strategy is considered an adaptation to maximize seed set at low cost, being related to variable environments, which present low pollinator availability and restricted growth conditions (Lord 1981; Culley \& Klooster 2007). Cleistogamy has evolved independently dozens of times in angiosperms, occurring in more than 228 genera belonging to 50 families (Culley \& Klooster 2007).

Based on the presence of the two floral types, cleistogamy may be classified into three categories (sensu Culley \& Klooster 2007). Dimorphic cleistogamy (1) is characterized by the presence of cleistogamous and chasmogamous flowers in the same population, but with different morphologies, resulting from distinct ontogenetic developments (e.g. Małobęcki et al. 2016). Thus, cleistogamous flowers are smaller due to reduction in corolla and size and/or number of stamens. In induced cleistogamy (2), there are no morphological and developmental differences between cleistogamous and chasmogamous flowers. Due to environmental factors, a potentially chasmogamous flower may not open and becomes cleistogamous, with complete anthesis as the only difference between these flowers. The occurrence of closed flowers and, therefore, with assured fertilization, is associated with unfavorable environmental conditions related to light, humidity, temperature and other limiting factors (e.g. Koike et al. 2015). Finally, complete cleistogamy (3) is the production of closed flowers only, being the less common type. In this sense, all flowers of the population are mandatorily self-pollinated (e.g. Suetsugu 2014).

\section{Resupinate dimorphy}

This is a floral dimorphism found in three Eplingiella spp. (Lamiaceae) (Harley et al. 2017). In this floral system, approximately half the population have exclusively resupinate flowers (upside down) while the other individuals have normal, non-resupinate ones. Resupination occurs as result of a $180^{\circ}$ pedicel rotation during flower bud stage. It occurs widely on Orchidaceae, so that in most species, the labellum goes to the lowest position of the flower (Nair \& Arditti 1991; Gibbs 2017). However, resupination seemed to be a fixed characteristic, being expected that all plants of a population would have only resupinate flowers (Gibbs 2017). In resupinate dimorphy, however, the presence of resupination is the difference between morphs of the same population (Harley et al. 2017; Gibbs 2017). It is likely that this floral dimorphism promotes disassortative pollination between morphs (Gibbs 2017), however it is yet to be directly tested.

Dichogamy

Dichogamy consists in temporal separation of sexual functions, either at different times of anthesis of staminate and pistillate flowers, or by the sequential ripening of the androecium or gynoecium within the same flower or inflorescence (Lloyd \& Webb 1986; Bertin \& Newman 1993; Harder et al. 2000). Although its exact frequency is unknown, dichogamy is common among angiosperms (Lloyd \& Webb 1986; Barrett 2003). This adaptive mechanism results in an asynchrony between pollen release and stigmatic receptivity, reducing physical interference between sexes as well as the probability of self-pollination and inbreeding depression, expanding the possibilities of cross-pollination (Faegri \& Pijl 1979; Lloyd \& Webb 1986; Harder et al. 2000). Dichogamy may be also combined with several other "outcrossing mechanisms", such as herkogamy and self-incompatibility (Lloyd \& Webb 1986). The absence of dichogamy is termed adichogamy or homogamy, but this latter is poorly known and not well-established (Faegri \& Pijl 1979; Lloyd \& Webb 1986). Dichogamy may be further divided into two types. In protogyny (1), the female component is functioning before the male (Lloyd \& Webb 1986; Bertin \& Newman 1993; Harder et al. 2000). In protandry (2) occurs the opposite, with male component functioning before the female one (see Lloyd \& Webb 1986; Çetinbaş \& Ünal 2014 to more details about dichogamy and subdivisions).

\section{Heterodichogamy}

Dichogamy may be non-synchronized in flowers of the same individual, but also occur in a synchronized manner, generating functional dioecy in the population. In heterodichogamy, protogyny and protandry are synchronously present in individuals of the same population (Renner 2001). Heterodichogamy is rare in angiosperms, occurring in about 50 species distribute in 12 families (Renner 2014), and can be divided in three types occurring with similar frequency (Pannell \& Verdú 2006). In type I, all individuals of a population are evenly dichogamous (protandrous or protogynous), differing in anthesis time. Thus, individuals in staminate phase provide those in pistillate phase with pollen (e.g. Kubitzki \& Kurs 1984). In types II and III occurs the coexistence of protandrous and protogynous individuals in the same population. The difference is that the change between staminate and pistillate phases may occur during the day (type II) or along flowering (type III). All heterodichogamy types potentiate cross-pollination and reduce interference between sexual functions within the same flower (characteristic of dichogamy itself).

Flexistyly

This is a complex floral system which combines both reciprocal herkogamy and heterodichogamy. In flexistyly, populations have protandrous and protogynous individuals (type II heterodichogamy; see above), which occur generally in the same frequencies (Li et al. 2001; Barrett 2002a). In 
addition to heterodichogamy, flexistylous species show the reciprocal movement of the stigma position through a vertical axis along the flowering period (Sun et al. 2007). There are two morphs in flexistyly according to stigma position and the type of dichogamy. The cataflexistylous morph (1) involves protandrous flowers with styles curved upwards during pollen dispersal in the morning. This causes the stigmas to be spatially separated from the anthers, avoiding contact with the pollinator. After the male function is finished, the style curves down in a position where the stigmas contact the pollinators. In the anaflexistylous morph (2) occurs the opposite. It has protogynous flowers, styles positioned downwards during the morning, contacting the pollinator and receiving pollen. In the afternoon, style curves upwards, reducing temporal and spatial sexual interference in bisexual flowers (Barrett 2002a; Li et al. 2002). Flexistyly has been reported mainly in Alpinia (Zingiberaceae) species (Li et al. 2001; 2002; Barrett 2002a). Flexistyly may also be included in "movements of floral whorls" (see below), but it was treated separately due to its peculiarities.

\section{Movements of floral whorls}

Floral movements have been appointed as mechanisms to avoid self-pollination (Ruan \& Silva 2011), and new evidence indicates that they reduce intrafloral male-female interference as well (Sun et al. 2007). However, some floral movements can promote self-pollination as a reproductive assurance mechanism (Ruan \& Silva 2011). Although many angiosperms can display different types of movements in several floral whorls, their adaptive significance have not been fully clarified yet (Ruan \& Silva 2011). The main movements of floral whorls related in the literature are those from gynoecium, androecium, or corolla. The motility is either insect induced or active. Due to their greater representativeness, we emphasize only the movements of the reproductive whorls (gyno- and androecium), but corolla movements may also be mentioned within this floral system.

Movements of the gynoecium (1) have been reported in 13 angiosperm families, related to both pollination and fertilization processes (Ruan \& Silva 2011). Different types of movements documented include: style elongation and curvature up or downwards (e.g. flexistyly; see above), stigma movement, closure of stigmatic lobe and gynoecium folding (e.g. Imbert \& Richards 1993; Hong et al. 2008; Freitas \& Sazima 2009; Ruan et al. 2010; Sritongchuay et al. 2010; Cardoso et al. 2018).

The movements of androecium (2) can be triggered in two ways (Mingxun 2010). In the first, movement occurs from the strength of the androecium itself being automatic or stimulated by the pollinators. In the second, it occurs through the forced movement of pollinators during pollination, pressing and directing the stamens to a specific flower region. The classification of the main movements involves: stimulated, cascade, fast and explosive, slow and simultaneous (see Mingxun 2010 to more details about androecium movements classifications). Among the different types of androecium movements reported in the literature occurs the filament elongation, cascade movements of stamens, pollen slipping, anther rotation and pollinarium reconfiguration (Ruan \& Silva 2011).

\section{(1.3) Incompatibility systems}

Self-incompatibility is defined as a genetic based inability of plants to produce fertile seeds after undergoing some level of selfing. Despite "self-sterility" may be used as a more general term comprising any adaptation that prevents self-fertilization, including when the reasons are simply unknown, self-incompatibility regards the rejection of self-pollen specifically due to genetically determined mechanisms (Gibbs 2014). This process occurs by means of a biochemical reaction that results in the interruption of pollen tube growth, fertilization or embryogenesis when pollen grains come from the same flower (i.e. selfpollination; Fig. 8), flowers present in the same individual (i.e. geitonogamous pollination; Fig. 8) or flowers from the same morph (intramorph cross-pollination, as in heterostyly; see topic 1.2) (Li \& Newbigin 2002; Glover 2007; Rea \& Nasrallah 2008). Self-incompatibility (SI) has been studied in several angiosperm families and is possibly controlled by a single locus, the "S" locus (Nettancourt 2001). This locus, however, does not represent only a single gene, but a region containing several genes that together control the self-incompatibility reaction (Glover 2007).

It is believed that the emergence of this mechanism was extremely important for the irradiation of the angiosperms during the Cretaceous period (Whitehouse 1950), since it favored cross-breeding and possibly contributed to increase the diversity of these plants (Allen \& Hiscock 2008). In this way, only the selection of physical and temporal strategies, such as the floral systems, is not enough to ensure cross-breeding. This occurs because the absence of a self-incompatibility system would entail serious ecoevolutionary disadvantages to the angiosperms, mainly due to the possible dominance of reproduction via endogamy. Thus, the self-incompatibility developed by angiosperms prevents endogamy, promotes cross-pollination, and increases genetic diversity (Iwano \& Takayama 2012).

The self-incompatibility systems are widely distributed along the main angiosperm lineages, occurring in about 71 families and covering approximately $60 \%$ of all species of the group (Hiscock \& Kues 1999; Allen \& Hiscock 2008). Taking into account the type of genetic control, the site of pistil where inhibition occurs and also the morphology of the studied flowers (homomorphic or heteromorphic), the self-incompatibility system may be then classified into four main types (reviewed in Gibbs 2014): gametophytic (GSI), homomorphic sporophytic (SSI), heteromorphic sporophytic 


\section{João Custódio Fernandes Cardoso, Matheus Lacerda Viana, Raphael Matias, Marco Túlio Furtado, Ana Paula de Souza \\ Caetano, Hélder Consolaro and Vinícius Lourenço Garcia de Brito}

(HetSI), and late-acting self-incompatibility systems, which are discussed below. The first three may be classified as "conventional self-incompatibility mechanisms" (sensu Gibbs 2014) because they are directly related to rejection of self-pollen at the stigma surface or when pollen tubes are growing along the style. On the other hand, in late-acting self-incompatibility, pollen tubes reach the ovary and they can even penetrate ovules before inhibition occurs.

\section{Gametophytic self-incompatibility (GSI)}

Gametophytic self-incompatibility occurs in flower homomorphic plants and is controlled by a single locus $S$ containing several alleles with absence of dominance. In this system, the pollen grain may express one or more alleles present on this locus, with the expression of incompatibility substances controlled by both ovules and pollen tubes, so that the recognition of equal alleles causes incompatibility and prevents fertilization (Li \& Newbigin 2002; Glover 2007; Gibbs 2014).

Accordingly, a given plant produces gametes with several different alleles and these are shared by their pollen grains. However, the incompatibility reaction will occur only when the haploid genotype expressed by the pollen grain is the same expressed by the ovules in the parental plant (Tanksley \& Loaiza-Figueroa 1985; Glover 2007). In this sense, populations with this system will present individuals compatible with each other, some semi-compatible, and others totally incompatible with each other (Oliveira \& Maruyama 2014). The general features that define this system are: presence of a single locus with several alleles, absence of dominance, semi-compatibility, wet stigma, bicellular pollen and interruption of pollen tube growth along the style (Oliveira \& Maruyama 2014).

The GSI system was extensively investigated in the family Solanaceae, being initially described in the genus Nicotiana (Glover 2007). It is widely distributed among angiosperms, being found in about 90 families such as Fabaceae, Papaveraceae, Plantaginaceae, Rosaceae, Scrophulariaceae and Solanaceae (Li \& Newbigin 2002; Franklin-Tong \& Franklin 2003).

Homomorphic sporophytic self-incompatibility (SSI)

This system also occurs in plant populations with only one floral type and is also genetically controlled by a single $S$ locus, which contains multiple alleles within the same population (Gibbs 1986; 1988; Mable et al. 2003). However, sporophytic systems are distinguished from gametophytic mainly by the presence of dominance between alleles and by the site of pollen tube interruption, which in SSI occurs in the stigma (Takayama \& Isogai 2005; Allen \& Hiscock 2008). This difference in the behavior of pollen grains occurs due to a temporal change in the action of the $S$ gene, which is activated before meiosis in the sporophyte and after meiosis in gametophyte (Pandey 1958), and also because of the deposition of proteins derived from $\mathrm{S}$ alleles in the exine (Heslop-Harrison 1968).

In plants with SSI, the dominant alleles expressed in the parental plant (diploid sporophyte) will be present on their pollen grains (haploid). The presence of similar alleles in the pollen receiving plant will trigger the incompatibility reaction, regardless of which allele is in the genome of the pollen grain itself (Hiscock \& Tabah 2003; Mable et al. 2003; Gibbs 2014). The main factors that characterize the SSI are: the presence of a single locus and several alleles, the presence of dominance between alleles, homomorphic flowers, dry stigma, tricellular pollen and interruption of pollen tube growth in the stigma (Oliveira \& Maruyama 2014).

The SSI system has a less extensive distribution in angiosperms when compared to GSI, and seems to have emerged more recently (Allen \& Hiscock 2008). This system has been investigated mainly in Asteraceae and Brassicaceae, due to their importance in agricultural production (Hinata et al. 1993). Nevertheless, it has also being reported in other families such as Betulaceae, Caryophyllaceae, Convolvulaceae and Polemoniaceae (Glover 2007; Allen \& Hiscock 2008).

\section{Heteromorphic sporophytic self-incompatibility (HetSI)}

This system shares functional characteristics with SSI, but involves flowers with different structures (e.g. pistil and/or stamen lengths) within the same population (Gibbs 1986; 2014). In HetSI the genetic control involves diallelic genes because it presents only two alleles responsible for the recognition and inhibition of pollen tube growth, being this rejection role of the parental plant (sporophyte) that produced the pollen grain (Ganders 1979; Gibbs 1986).

The HetSI system is found mainly in heterostylous groups (see topic 1.2), despite being also reported in the Sterculiaceae, which presents homomorphic species (Allen \& Hiscock 2008). Species of the Primula genus constitute the classic study model for HetSI (Mather 1950; Pamela \& Dowrick 1956), in which the long-styled morph is homozygous recessive (ss) while the short-styled is heterozygous (Ss). In this sense, after crosses between individuals with the same morphology (intramorph), the allele expressed by the pollen grain will be recognized by the parental plant (sporophyte). As the short-styled morph has the dominant allele $S$, it will always be expressed in intramorph cross-pollination (between short-styled individuals), thus inhibiting the pollen tube growth. In intramorph crosses involving the long-styled morph, the inhibition will occur regardless of the allele expressed by the pollen grain, since they are both ss (Gibbs 1986).

The main features of the HetSI are: a single locus with two alleles, relationship of dominance between them, self- 
and intramorph incompatibility, dimorphic or polymorphic flowers and secondary dimorphisms (sizes of: anthers, styles stigmatic papillae and pollen grains) (Oliveira \& Maruyama 2014). The distribution of this system in angiosperms occurs in different lineages and is reported in 25 families (Barrett 1992). The evolution of HetSI occurred independently several times during the diversification of angiosperms (Gibbs 1986), with most of the groups being distylous, and found in only four tristylous families (Connaraceae, Lythraceae, Oxalidaceae and Pontederiaceae) (Nettancourt 2001).

\section{Late-acting self-incompatibility (LSI) (ovarian incompatibility, pistillate sorting)}

This is a homomorphic incompatibility system in which pollen tubes from self-pollination are not inhibited before reaching the ovary, and may even penetrate the ovules (Gibbs 1988; Bittencourt Júnior 2017). Evidences of its existence have been recorded for more than 50 years (e.g. Cope 1962). However, late-acting self-incompatibility has long been considered a rare phenomenon in nature (Nettancourt 1977). The LSI is still poor understood in angiosperms, found in species of families and genera with taxonomically close relationships (Gibbs 2014). Several families present species with late-acting self-incompatibility, such as Apocynaceae (Araujo et al. 2011), Bignoniaceae (Bittencourt Júnior 2017), Fabaceae (Borges et al. 2008) and Malvaceae (Souza \& Venturieri 2010).

There are four described situations in which the lateacting incompatibility occur (sensu Bittencourt Júnior 2017): the pollen tubes of self-pollen grow until the ovary, but are inhibited before reaching the ovules (1); the ovules are penetrated, but the inhibition occurs in the micropyle or nucellus (2); pollen tubes penetrate the ovules but a failure happens during syngamy, after the male gametes are deposited in the embryo sac (3); self-fertilization occurs but embryogenesis does not (4).

\section{(1.4) Mating systems}

The different terminologies within the mating systems consider the mode of gene transfer from one generation to the next through sexual reproduction. It is related to the genetic relation between gametes involved, specifically regarding the source of the male gamete (self-related or not). Important determinants of mating systems of a given plant are the rate of maternal autogamy and male success through pollen grains dispersal (Barrett 1998; Neal \& Anderson 2005). It is worth mentioning that gene transmission in angiosperms depends on several factors, such as movement of pollinators and/or abiotic vectors as well as aspects of the sexual, floral and incompatibility systems discussed before. The different mating modes in plants are discussed below.

\section{Autogamy (self-fertilization, self-fecundation)}

Autogamy consists in the fertilization of male and female gametes from the same flower after self-pollination (Fig. 8), which may happen only in bisexual flowers (Richards 1997). Therefore, it is always associated to self-compatibility. The evolution of autogamy from xenogamy (see below) is one of the major evolutionary transitions in plant mating systems (Barrett 2010b). Some authors consider autogamous plants only those in which the fertilization occurs after deposition of self-pollen spontaneously, without interference of any pollen vector (also called autonomous autogamy; sensu Eckert 2000). Some floral mechanisms may favor autonomous autogamy such as incomplete protogyny, style curvature, absence or temporal reduction in herkogamy, floral closure, and corolla abscissions (Goodwillie \& Weber 2018). However, self-pollen deposition may also occur through pollinator visiting behavior, which would also lead to autogamy (facilitated autogamy; sensu Lloyd 1992). Herein, we consider autogamous those plants in which self-fertilization successfully occurs, regardless the selfpollen deposition mechanism. In many cases, autogamy functions as a reproductive assurance mechanism when pollinators are scarce or inefficient, contributing to maintain

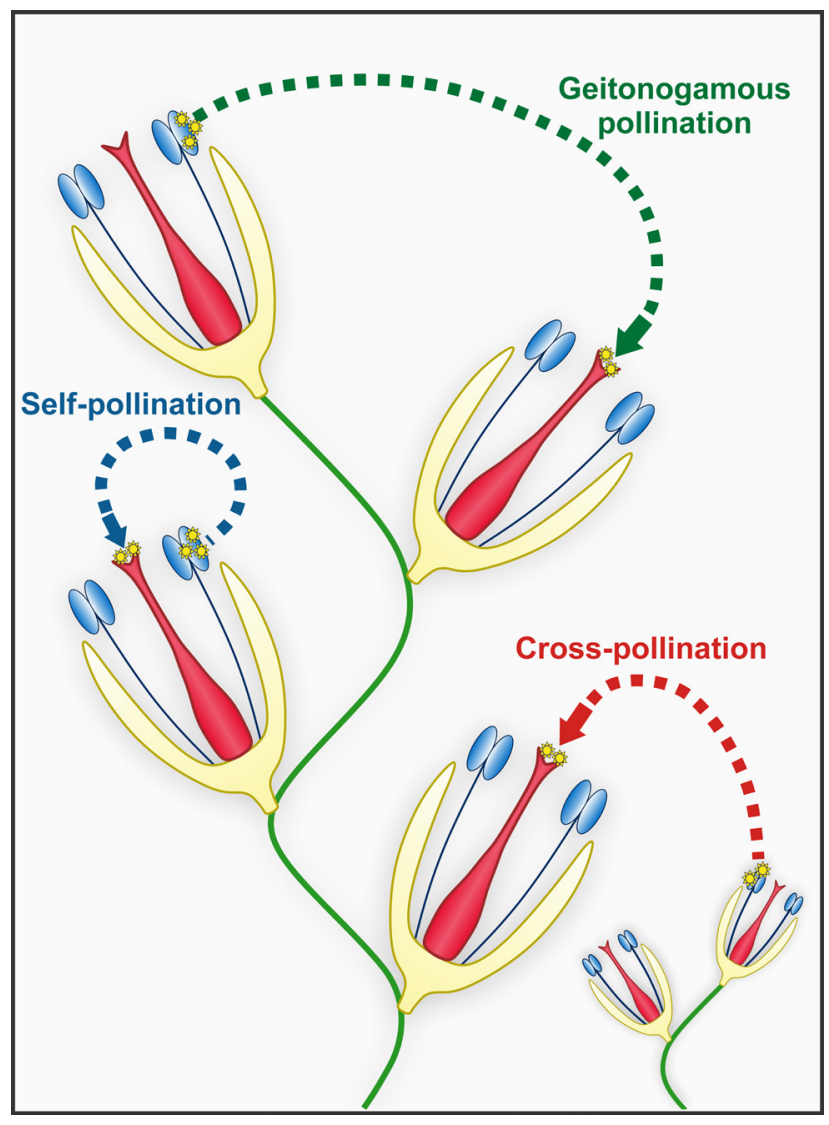

Figure 8. Different types of pollination according to the source of pollen. Stamens and pistils are expressed respectively in blue and red shades. 


\section{João Custódio Fernandes Cardoso, Matheus Lacerda Viana, Raphael Matias, Marco Túlio Furtado, Ana Paula de Souza \\ Caetano, Hélder Consolaro and Vinícius Lourenço Garcia de Brito}

reproductive success (Lloyd \& Schoen 1992). Nevertheless, this reproductive strategy may reduce genetic variability and increase inbreeding depression levels (Lloyd \& Schoen 1992). In genetic studies, plants predominantly autogamous present less than $5 \%$ of cross-fertilization (Canuto et al. 2014). Autogamy is a reproductive trait commonly found in invasive, pioneer and annual colonizer species that occur in forest gaps and edges, allowing high reproductive rates and rapid occupation of the environment (Williamson \& Fitter 1996; Holsinger 2000; Barrett 2010b).

\section{Geitonogamy}

Consists in the fertilization between gametes from different flowers of the same individual after geitonogamous pollination (Fig. 8) (Lloyd \& Schoen 1992; Richards 1997; Eckert 2000). Geitonogamy may occur in bisexual and unisexual flowers (in this case in monoecious species). The concept of geitonogamy may be confusing, perhaps because the fertilization process depends on pollination involving different flowers, as well as xenogamy (see below). Indeed, both geitonogamy and xenogamy sometimes are called allogamy, since they promote pollination among different flowers (Richards 1997). In contrast with xenogamy, geitonogamy may produce progenies genetically similar to that of autogamous angiosperms since the gametes come from the same plant. Thereby, geitonogamy may also be considered a special case of self-fertilization. However, it is known that the plants have metameric growth and modular body, and new mutations in the vegetative and reproductive meristems within the individual can be transmitted to its progeny (Barrett \& Harder 2017). Thus, geitonogamy has a greater potential to generate genetic variability than autogamy. Geitonogamy has the ecological properties of cross-pollination and the genetic properties similar to those of self-fertilization (Lloyd \& Schoen 1992; Richards 1997). Unlike autogamy, geitonogamy provides little or no reproductive assurance, since it requires a pollen vector to perform pollination (Eckert 2000).

\section{Xenogamy (cross-fertilization, cross-fecundation)}

Xenogamy is the fertilization of gametes from flowers of different individuals after cross-pollination (Fig. 8) (Richards 1997). In this type of fertilization, plants do not transmit their entire genotypes to the next generation (as in autogamy, geitonogamy and apomixis; see topic 2.1), but only part of their alleles. This promotes an increase in genetic variability through new combinations (Simpson 2006). Every generation, new individuals with allelic constitutions different from the parental will emerge. This genetic diversity in the population may allow individuals to adapt to a wide range of environmental conditions and increase the likelihood of survival and evolutionary change (Simpson 2006). A disadvantage of xenogamy is that it requires a pollen vector to transfer gametes between plants. If individuals are distant from each other or pollinators are scarce, sexual reproduction will not be favored (Simpson 2006). Obligatory xenogamous plants are those that reproduce preferably through cross-pollination (above $95 \%$ of the fruits formed via xenogamy) (Canuto et al. 2014). This reproductive strategy is the most frequent in angiosperms (Ferrer \& Good 2012). Obligatory xenogamy occurs in dioecious species or in those with incompatibility systems, being the latter considered an alternative for bisexual flowers to ensure xenogamy (Richards 1997).

\section{(2) Asexual reproduction}

Besides the sexual reproduction, plants are also able to reproduce asexually. This occurs in the absence of meiosis and fusion of gametes, generating individuals genetically identical or very similar to the parental plant (Richards 1997; Holsinger 2000; Eckert 2002). Asexual reproduction can be divided in two basic types: vegetative propagation and apomixis (Holsinger 2000; Silvertown 2008). Since the vegetative propagation has not been understood as a breeding system, herein we will only deal with apomixis.

\section{(2.1) Apomictic systems}

Apomixis is defined as asexual reproduction through seeds (Asker \& Jerling 1992; Hand \& Koltunow 2014). This reproductive mode is derived from sexual reproduction and it is expressed through temporal and spatial alterations of sexual developmental pathways (Carman 1997; Grimanelli et al. 2003; Koltunow \& Grossniklaus 2003; Hand \& Koltunow 2014). Apomixis combines the asexual mode while retaining the benefits of seed reproduction, such as dispersion ability and dormancy. This may ensure reproductive success, maintaining populations where conditions for sexual reproduction are compromised (Richards 1997). Moreover, due to its uniparental reproductive ability, which allows them to found populations with a single seed, apomictic species have advantages in colonization scenarios (Baker 1967; Richards 1997).

The apomixis might be viewed as a deregulation in the sexual process due to hybridization events followed by polyploidization (Carman 1997; Koltunow \& Grossniklaus 2003). It is believed that the presence of two genomes in an allopolyploid differing in the female developmental patterns leads to an asynchronous expression of the duplicate genes, resulting in apomixis (Carman 1997; 2007). Accordingly, most of the apomictic populations are polyploid (Asker \& Jerling 1992; Carman 1997). The polyploidy may be important because it induces epigenetic changes in gene regulation, avoiding mechanisms that tend to synchronize divergent signals in diploid hybrids. It allows the expression of developmental apomictic pathways (Carman 2007). 
Apomixis occurs in approximately 78 angiosperm families and seems to have arisen independently multiple times (Hojsgaard et al. 2014). However, the occurrence of apomixis is clearly concentrated in certain groups, such as Asteraceae, Melastomataceae, Orchidaceae, Poaceae and Rosaceae (Carman 1997; Naumova 2008; Santos et al. 2012; Hojsgaard et al. 2014). From an evolutionary viewpoint, apomixis has been correlated with high taxonomic diversity within some clades (Hojsgaard et al. 2014), contradicting the previous premise that this mode of reproduction would be an "evolutionary dead end" (Stebbins 1950).

In general, apomictic groups have relatively low genetic variability among individuals. However, the different apomictic mechanisms (apospory, diplospory or adventitious embryony) are in association with different levels of sexual reproduction and diverse selective pressures that interfere with the production of viable pollen grains. This leads to higher degrees of genetic diversity within populations (Whitton et al. 2008; Tucker \& Koltunow 2009; Dias et al. 2017).

The classification of the apomictic systems presented in the next topics is based on: the embryo origin (1): gametophytic or sporophytic apomixis; the necessity of polar nuclei fertilization to endosperm development (2): autonomous apomixis or pseudogamy; and whether sexual and asexual reproduction occur concomitantly (3): facultative or obligate apomixis.

\section{Gametophytic apomixis}

In this kind of apomixis, the embryo develops through parthenogenesis from the egg cell of an unreduced embryo sac (Asker \& Jerling 1992; Koltunow \& Grossniklaus 2003; Hand \& Koltunow 2014) and it is subdivided into two categories: diplospory and apospory. In the first, the unreduced embryo sac is originated from the megaspore mother cell by suppression or alteration in meiosis. In apospory, the unreduced embryo sac originates from a somatic ovule cell (Asker \& Jerling 1992; Koltunow \& Grossniklaus 2003; Hand \& Koltunow 2014). Unlike diplospory, a reduced embryo sac may develop concurrently with the aposporic one, once the megaspore mother cell is not compromised by apomictic events (Nogler 1984; Asker \& Jerling 1992). Diplospory is reported, for example, in Asteraceae (Noyes 2007), Melastomataceae (Caetano et al. 2013), and Rosaceae (Talent 2009). Apospory is often found in Poaceae (Carman 1997) and Rosaceae (Dickinson et al. 2007; Talent 2009).

\section{Sporophytic apomixis (adventitious embryony)}

In sporophytic apomixis (adventitious embryony), the embryo originates from somatic cells of the ovule, usually from the nucellus or integument, and it commonly develops in parallel with the sexual embryo (Nogler 1984;
Bicknell \& Koltunow 2004). Sporophytic apomixis is the most common apomictic mechanism in angiosperms. It is reported in Bignoniaceae (Alves et al. 2016), Malvaceae (Mendes-Rodrigues et al. 2005), Rutaceae (Lakshmanan \& Ambegaokar 1984), among others (Naumova 2008). The production of multiple embryos per seed (polyembryony) is a common phenomenon related to this apomictic mechanism (Richards 2003). In certain contexts, polyembryony may be advantageous, since it increases the chances of at least one seedling to establish from a single seed (Ladd \& Cappuccino 2005; Mendes-Rodrigues et al. 2012). In addition, polyembryonic seeds allow the coexistence of sexual and asexual embryos, so different genotypes and levels of genetic variability can be found in the same seed (Batygina \& Vinogradova 2007). On the other hand, the formation of multiple embryos in a single seed can cause embryo morphological anomalies due to resource competition, negatively affecting embryo and seedling survival (Mendes-Rodrigues et al. 2012; Caetano et al. 2018). In this sense, programmed cell death in polyembryonic seed development has been reported as a mechanism to prevent competition between embryos and ensure the survival of at least one (Filonova et al. 2002).

\section{Autonomous apomixis}

Autonomous apomixis occurs when embryo and the endosperm can develop independently of fertilization (Nogler 1984; Asker \& Jerling 1992). In this case, the species have the advantages of total pollen/pollinator independence, and consequent reproductive assurance (Hörandl 2010). Autonomous endosperm development prevails in Asteraceae (Noyes 2007) and Melastomataceae species (Caetano et al. 2013; 2018), however, in general, it is uncommon in apomictic plants (Koltunow \& Grossniklaus 2003).

\section{Pseudogamy}

Unlike in autonomous apomictic species, pseudogamous ones depend on the fertilization of the polar nucleus or nuclei by a male gamete to endosperm development (Nogler 1984; Asker \& Jerling 1992). This dependence of the male gamete is considered as a selective pressure in the maintenance of production of some viable pollen grains (Noirot et al. 1997). Pseudogamy is a common phenomenon among aposporous apomictic species, as in Poaceae and Rosaceae (Nogler 1984; Asker \& Jerling 1992; Savidan 2000). Similarly, genera with adventitious embryony are frequently pseudogamous (Koltunow \& Grossniklaus 2003; Whitton et al. 2008).

\section{Facultative apomixis}

This type is recognized when the apomixis occurs in parallel with sexual reproduction. Indeed, most of apomictic 


\section{João Custódio Fernandes Cardoso, Matheus Lacerda Viana, Raphael Matias, Marco Túlio Furtado, Ana Paula de Souza \\ Caetano, Hélder Consolaro and Vinícius Lourenço Garcia de Brito}

species retain this ability (Asker \& Jerling 1992; Koltunow \& Grossniklaus 2003; Savidan 2007). Thereby, seeds can be produced through both asexual and sexual processes. Pseudogamous species are usually facultative apomictics. The balance between asexual and sexual modes seems to be influenced by genetic and environmental factors (Asker \& Jerling 1992; Koltunow \& Grossniklaus 2003). This reproductive flexibility confers some genetic variability to these species, allowing a better adaptability to different environmental conditions (Richards 1997). Besides that, sexuality in apomictic lineages may mask deleterious mutations, preventing genomic decay and extinction (Hojsgaard \& Hörandl 2015).

\section{Obligate apomixis}

It is characterized by reproduction exclusively via apomixis (Asker \& Jerling 1992; Savidan 2007). Obligate apomictic species present lower pollen viability compared to facultative ones, once the former do not require such resource for reproduction. However, some levels of genetic variability may still exist among obligate apomictics through different pathways, such as somatic recombination, chromosomal gain or loss, mutations and the occurrence of restitutional meiosis (Richards 1996; Dias et al. 2017). Apomixis is rarely obligate in angiosperms, since most of apomictic species produce descendants through sexual and asexual forms (Hojsgaard \& Hörandl 2015).

\section{Final considerations}

Consistency and unambiguous terminology in any field boosts progress, while inconsistency hinders it. Thus, authors should explicitly define terminologies in scientific publications on angiosperm reproductive biology (Neal \& Anderson 2005). In a terminological viewpoint, previous reviews brought only few terms, often without systematic arrangement/definition, perhaps because their aims were other rather than the nomenclatural classification. Here, we summarized and proposed a framework comprising the main mechanisms angiosperms display that guarantee and optimize reproduction through seeds. As an attempt to organize strategies in our artificial classification, each term was discussed separately. Thus, it is worth highlighting again that the terms are not mutually exclusive. In this sense, a given plant may, at the same time, display a sort of different sexual, floral, incompatibility, mating, and apomictic systems. The concomitance of several mechanisms is common in nature and may improve reproductive success in the different angiosperms lineages.

The variety of sexual systems compiled here can be thought, at the same time, as causes and consequences of angiosperms huge diversity. This has led to a wideranging research field, with terminologies used in several ways, often arbitrarily. Research on plant reproductive systems are among the most popular and dynamic among scientists of several areas such as ecology and evolution. In addition, the field of reproductive biology is going through a huge breakthrough, marked by a new era of methods and hypothesis testing in a changing world (Barrett 2010b). Thus, terminological unification is of paramount importance for the communication and cohesion of this important area of knowledge. We expect to benefit it with consistent and well-defined applications of these reproductive systems terminologies.

\section{Acknowledgements}

We are grateful to Paulo Eugênio Oliveira for his reading and contributions, which gave a new soul to the manuscript. This review is dedicated to him. We also acknowledge Pedro $\mathrm{J}$. Bergamo and two anonymous reviewers for initial inputs on the texts and systems. This text was produced as part of the annual course Fundaments and Frontiers in Pollination Ecology held in Uberlândia, Brazil, 2017.

\section{References}

Allen AM, Hiscock SJ. 2008. Evolution and phylogeny of selfincompatibility systems in angiosperms. In: Franklin-Tong VE. (eds.) Self-incompatibility in flowering plants: evolution, diversity, and mechanisms. Berlin, Springer-Verlag. p. 73-101.

Alves MF, Duarte MO, Bittencourt Júnior NS, Oliveira PE, Sampaio DS. 2016. Sporophytic apomixis in polyembryonic Handroanthus serratifolius (Vahl) S. Grose (Bignoniaceae) characterizes the species as an agamic polyploid complex. Plant Systematics and Evolution 302: 651-659.

Araujo A, Duarte L, Quirino M, Glebya Z, Machado IC. 2011. Fenologia reprodutiva, biologia floral e polinização de Allamanda blanchetii, uma Apocynaceae endêmica da Caatinga. Brazilian Journal of Botany 34: 211-222.

Armbruster WS, Corbet SA, Vey AJM, Liu S, Huang S. 2014. In the right place at the right time: Parnassia resolves the herkogamy dilemma by accurate repositioning of stamens and stigmas. Annals of Botany 113: 97-103.

Asker SE, Jerling L. 1992. Apomixis in plants. Boca Raton, CRC Press.

Baker HG. 1967. Support for Baker's law - as a rule. Evolution 21: 853-856.

Barrett SCH. 1992. Heterostylous genetic polymorphisms: Model systems for evolutionary analysis. In: Barrett SCH. (ed.) Evolution and function of heterostyly. Berlin Heidelberg New York, Springer. p. 1-29.

Barrett SCH. 1998. The evolution of mating strategies in flowering plants. Trends in Plant Science 3: 335-341.

Barrett SCH. 2002a. The evolution of plant sexual diversity. Nature Reviews Genetics 3: 274-284.

Barrett SCH. 2002b. Sexual interference of the floral kind. Heredity 88: 154-159.

Barrett SCH. 2003. Mating strategies in flowering plants: the outcrossingselfing paradigm and beyond. Philosophical Transactions of the Royal Society B 358: 991-1004.

Barrett SCH. 2010a. Darwin's legacy: the forms, function and sexual diversity of flowers. Philosophical Transactions of the Royal Society B 365: 351-368.

Barrett SCH. 2010b. Understanding plant reproductive diversity. Philosophical Transactions of the Royal Society B 365: 99-109.

Barrett SCH, Harder LD. 2017. The ecology of mating and its evolutionary consequences in seed plants. Annual Review of Ecology, Evolution and Systematics 48: 135-157. 
Barrett SCH, Hough J. 2013. Sexual dimorphism in flowering plants. Journal of Experimental Botany 64: 67-82.

Barrett SCH, Jesson LK, Baker AM. 2000. The evolution and function of stylar polymorphisms in flowering plants. Annals of Botany 85: 253-265.

Barrett SCH, Shore JS. 2008. New insights on heterostyly: comparative biology, ecology and genetics. In: Franklin-Tong VE. (ed.) Selfincompatibility in flowering plants: evolution, diversity, and mechanisms. Berlin, Springer-Verlag. p. 3-32.

Batygina TB, Vinogradova GY. 2007. Phenomenon of polyembryony. Genetic heterogeneity of seeds. Russian Journal of Developmental Biology 38: 126-151.

Bawa KS. 1980. Evolution of dioecy in flowering plants. Annual Review of Ecology and Systematics 11: 15-39.

Bawa KS, Beach JH. 1981. Evolution of sexual systems in flowering plants. Annals of the Missouri Botanical Garden 68: 254-274.

Bawa KS, Beach JH. 1983. Self-incompatibility systems in the Rubiaceae of a tropical lowland wet forest. American Journal of Botany 70: 1281-1288.

Bertin RI. 1982. The evolution and maintenance of andromonoecy. Evolutionary Theory 6: 25-32.

Bertin RI, Connors DB, Kleinman HM. 2010. Differential herbivory on disk and ray flowers of gynomonoecious asters and goldenrods (Asteraceae). Biological Journal of the Linnean Society 101: 544-552.

Bertin RI, Newman CM. 1993. Dichogamy in angiosperms. The Botanical Review 59: 112-152.

Bicknell RA, Koltunow AM. 2004. Understanding apomixis: recent advances and remaining conundrums. The Plant Cell 16: 228-245.

Bittencourt Júnior NS. 2017. Evidence for post-zygotic self-incompatibility in Handroanthus impetiginosus (Bignoniaceae). Plant Reproduction 30: 69-79.

Borges LA, Sobrinho MS, Lopes AV. 2008. Phenology, pollination, and breeding system of the threatened tree Caesalpinia echinata Lam. (Fabaceae), and a review of studies on the reproductive biology in the genus. Flora 204: 111-130.

Buchmann SL. 1983. Buzz pollination in angiosperms. In: Jones CE, Little RJ. (eds.) Handbook of experimental pollination biology, New York, Van Nostrand Reinhold Company. p. 73-113.

Caetano APS, Cortez PA, Teixeira SP, Oliveira PE, Carmello-Guerreiro SM. 2018. Unusual diversity of apomictic mechanisms in a species of Miconia, Melastomataceae. Plant Systematics and Evolution 304: 343-355.

Caetano APS, Simao DG, Carmo-Oliveira R, Oliveira PE. 2013. Diplospory and obligate apomixis in Miconia albicans (Miconieae, Melastomataceae) and an embryological comparison with its sexual congener $M$. chamissois. Plant Systematics and Evolution 299: 1253-1262.

Canuto JZ, Alves-Pereira A, Côrtes MC. 2014. Genética nos estudos com polinização. In: Rech AR, Agostini K, Oliveira PE, Machado IC. (eds.) Biologia da polinização. Rio de Janeiro, Projeto cultural. p. 439-460.

Cardoso JCF, Deus FF, Silva SCS, Oliveira PE. 2018. Bow to the middle: reproductive system and style behaviour of Tococa guianensis, a widespread Melastomataceae from the Neotropics. Plant Systematics and Evolution 304: 259-267.

Carman JG. 1997. Asynchronous expression of duplicate genes in angiosperm may cause apomixis, bispory, tetraspory, and polyembryony. Biological Journal of the Linnean Society 61: 51-94.

Carman JG. 2007. Do duplicate genes cause apomixis? In: Hörandl E, Grossniklaus U, Dijk PJ, Sharbel T. (eds.) Apomixis: evolution, mechanisms and perspectives. Lichtenstein, ARG Ganter Verlag KG. p. 169-194.

Çetinbaş A, Ünal M. 2014. An overview of dichogamy in angiosperms. Research in Plant Biology 4: 09-27.

Charlesworth B, Charlesworth D. 1978. A model for the evolution of dioecy and gynodioecy. The American Naturalist 112: 975-997.

Charlesworth B, Charlesworth D. 2000. The degeneration of Y chromosomes. Philosophical Transactions of the Royal Society B 355: 1563-1572.

Charlesworth D. 1981. A further study of the problem of the maintenance of females in gynodioecious species. Heredity 46: 27-39.

Charlesworth D. 1984. Androdioecy and the evolution of dioecy. Biological Journal of the Linnean Society 22: 333-348.
Charlesworth D. 2002. Plant sex determination and sex chromosomes. Heredity 88: 94-101.

Charlesworth D. 2006. Evolution of plant breeding systems. Current Biology 16: R726-R735.

Charlesworth D. 2013. Plant sex chromosome evolution. Journal of experimental botany 64: 405-420.

Charlesworth D. 2015. Plant contributions to our understanding of sex chromosome evolution. New Phytologist 208: 52-65.

Charlesworth D, Charlesworth B. 1979. A model for the evolution of distyly. The American Naturalist 114: 467-498.

Charlesworth D, Willis JH. 2009. Fundamental concepts in genetics: the genetics of inbreeding depression. Nature Reviews Genetics 10: 783-796.

Consolaro H, Silva SCS, Oliveira PE. 2011. Breakdown of distyly and pinmonomorphism in Psychotria carthagenensis Jacq. (Rubiaceae). Plant Species Biology 26: 24-32.

Cope FW. 1962. The mechanism of pollen incompatibility in Theobroma cacao L. Heredity 17: 157-182.

Costa J, Castro S, Loureiro J, Barrett SCH. 2016. Variation in style morph frequencies in tristylous Lythrum salicaria in the Iberian Peninsula: the role of geographical and demographic factors. Annals of Botany 117: 331-340.

Crawley MJ. 1997. Sex. Crawley MJ. (ed.) Plant ecology. Oxford, Blackwell Publishing. p. 156-213.

Cruden RW, Lloyd RM. 1995. Embryophytes have equivalent sexual phenotypes and breeding systems: why not a common terminology to describe them? American Journal of Botany 82: 816-825.

Culley TM, Klooster MR. 2007. The cleistogamous breeding system: a review of its frequency, evolution, and ecology in angiosperms. The Botanical Review 73: 1-30.

Darwin CR. 1877. The different forms of flowers on plants of the same species. London, John Murray.

Dias ACC, Serra AC, Sampaio DS, Borba EL, Bonetti AM, Oliveira PE. 2017. Unexpectedly high genetic diversity and divergence among populations of the apomictic Neotropical tree Miconia albicans. Plant Biology 20: 244-251.

Dickinson TA, Lo E, Talent N. 2007. Polyploidy, reproductive biology, and Rosaceae: understanding evolution and making classifications. Plant Systematics and Evolution 266: 59-78.

Dornier A, Dufay M. 2013. How selfing, inbreeding depression, and pollen limitation impact nuclear-cytoplasmic gynodioecy: a model. Evolution 67: 2674-2687.

Dulberger R. 1992. Floral polymorphisms and their functional significance in the heterostylous syndrome. In: Barrett SCH. (eds.) Evolution and function of heterostyly. Berlin, Springer Verlag. p. 41-84.

Eckert CG. 2000. Contributions of autogamy and geitonogamy to selffertilization in a mass-flowering, clonal plant. Ecology 81: 532-542.

Eckert CG. 2002. The loss of sex in clonal plants. Evolutionary Ecology 15: 501-520.

Faegri KL, Pijl L. 1979. The principles of pollination ecology, 3nd. edn. New York, Pergamon.

Ferrer MM, Good SV. 2012. Self-sterility in flowering plants: preventing self-fertilization increases Family diversification rates. Annals of Botany 110: 535-553.

Ferrero V, Arroyo J, Castro S, Navarro L. 2012. Unusual heterostyly: style dimorphism and self-incompatibility are not tightly associated in Lithodora and Glandora (Boraginaceae). Annals of Botany 109: 655-665.

Ferrero V, Arroyo J, Vargas P, Thompson JD, Navarro L. 2009. Evolutionary transitions of style polymorphisms in Lithodora (Boraginaceae). Perspectives in Plant Ecology, Evolution and Systematics 11: 111-125.

Filonova LH, Arnold S, Bozhkov PV. 2002. Programmed cell death eliminates all but one embryo in a polyembryonic plant seed. Cell Death and Differentiation 9: 1057-1062.

Franklin-Tong V, Franklin C. 2003. Gametophytic self-incompatibility inhibits pollen tube growth using different mechanisms. Trends in Plant Science 8: 598-605.

Freeman DC, Harper KT, Charnov EL. 1980. Sex change in plants: old and new observations and new hypotheses. Oecologia 47: 222-232. 


\section{João Custódio Fernandes Cardoso, Matheus Lacerda Viana, Raphael Matias, Marco Túlio Furtado, Ana Paula de Souza Caetano, Hélder Consolaro and Vinícius Lourenço Garcia de Brito}

Freeman DC, McArthur ED, Harper KT, Blauer AC. 1981. Influence of environment on the floral sex ratio of monoecious plants. Evolution 35: 194-197.

Freitas L, Sazima M. 2009. Floral biology and mechanisms of spontaneous self-pollination in five neotropical species of Gentianaceae. Botanical Journal of the Linnean Society 160: 357-368.

Fryxell PA. 1957. Mode of reproduction of higher plants. The Botanical Review 23: 135-233.

Ganders FR. 1979. The biology of heterostyly. New Zealand Journal of Botany 17: 607-635.

Gibbs PE. 1986. Do homomorphic and heteromorphic self-incompatibility systems have the same sporophytic mechanism? Plant Systematics and Evolution 154: 285-323.

Gibbs PE. 1988. Self-incompatibility mechanisms in flowering plants: some complications and clarifications. Lagascalia 15: 17-28.

Gibbs PE. 2014. Late-acting self-incompatibility - the pariah breeding system in flowering plants. New Phytologist 203: 717-734.

Gibbs PE. 2017. Head over heels about floral polymorphism: a novel floral dimorphism based on resupination. Plant Ecology \& Diversity 10: 1-3.

Glover BJ. 2007. Understanding flowers and flowering: an integrated approach. Oxford, Oxford University Press.

Godin VN, Demyanova EI. 2013. About extent of gynodioecy in Angiosperms. Botaniceskij Zurnal 98: 1465-1487.

Goodwillie C, Weber JJ. 2018. The best of both worlds? A review of delayed selfing in flowering plants. American Journal of Botany 105: 641-655.

Grimanelli D, García M, Kaszas E, Perotti E, Leblanc O. 2003. Heterochronic expression of sexual reproductive programs during apomitic development in Tripsacum. Genetics 165: 1521-1531.

Hand ML, Koltunow AM. 2014. The genetic control of apomixis: asexual seed formation. Genetics 197: 441-450.

Harder LD, Barrett SCH, Cole WW. 2000. The mating consequences of sexual segregation within inflorescences of flowering plants. Proceedings of the Royal Society of London B 267: 315-320.

Harley RM, Giulietti AM, Abreu IS, Bitencourt C, Oliveira FF, Endress PK. 2017. Resupinate Dimorphy, a novel pollination strategy in twolipped flowers of Eplingiella (Lamiaceae). Acta Botanica Brasilica 31: 102-107.

Heilbuth J. 2000. Lower species richness in dioecious clades. The American Naturalist 156: 221-241.

Heslop-Harrison J. 1968. Pollen wall development. Science 161: 230-237.

Hinata K, Watanabe M, Toriyama K, Isogai A. 1993. A review of recent studies on homomorphic self-incompatibility. International Review of Cytology 143: 257-296.

Hiscock SJ, Kües U. 1999. Cellular and molecular mechanisms of sexual incompatibility in plants and fungi. International Review of Cytology 193:165-295.

Hiscock SJ, Tabah DA. 2003. The different mechanisms of sporophytic self-incompatibility. Philosophical Transactions of the Royal Society B 358: 1037-1045

Hojsgaard D, Hörandl E. 2015. A little bit of sex matters for genome evolution in asexual plants. Frontiers in Plant Science 6: 82.

Hojsgaard D, Klatt S, Baier R, Carmam JG, Hörandl E. 2014. Taxonomy and biogeography of apomixis in angiosperms and associated biodiversity characteristics. Critical Reviews in Plant Sciences 33: 414-427.

Holsinger KE. 2000. Reproductive systems and evolution in vascular plants. Proceedings of the National Academy of Sciences 97: 7037-7042.

Hong L, Shen H, Ye WH, Cao HL, Wang ZM. 2008. Secondary pollen presentation and style morphology in the invasive weed Mikania micrantha in South China. Botanical Studies 49: 253-260.

Hörandl E. 2010. The evolution of self-fertility in apomictic plants. Sexual Plant Reproduction 23: 73-86.

Imbert FM, Richards JH. 1993. Protandry, incompatibility and secondary pollen presentation in Cephalantus occidentalis (Rubiaceae). American Journal of Botany 80: 395-404.

Iwano M, Takayama S. 2012. Self/non-self discrimination in angiosperm self-incompatibility. Current Opinion in Plant Biology 15: 78-83.

Janzen DH. 1977. A note on optimal mate selection by plants. The American Naturalist 111: 365-371.
Jernstedt JA. 1982. Floral variation in Chlorogalum angustifolium (Liliaceae). Madroño 29: 87-94.

Jesson LK, Barrett SCH. 2002a. Solving the puzzle of mirror-image flowers. Nature 417: 707

Jesson LK, Barrett SCH. 2002b. Enantiostyly in Wachendorfia (Haemodoraceae); the influence of reproductive systems on the maintenance of the polymorphism. American Journal of Botany 89: 253-263.

Jesson LK, Barrett SCH. 2003. The comparative biology of mirror-image flowers. International Journal of Plant Sciences 164: S237-S249.

Jesson LK, Barrett SCH, Day T. 2003. A theoretical investigation of the evolution and maintenance of mirror-image flowers. The American Naturalist 161: 916-931.

Jesson LK, Kang J, Wagner S, Barrett SCH, Dengler NG. 2002. The development of mirror-image flowers. American Journal of Botany 90: 181-194.

Jong TJ, Klinkhamer PGL. 2005. Evolutionary ecology of plant reproductive strategies. New York, Cambridge University Press.

Jong TJ, Shmida A, Thuijsman F. 2008. Sex allocation in plants and the evolution of monoecy. Evolutionary Ecology Research 10: 1087-1109.

Käfer J, Marais GA, Pannell JR. 2017. On the rarity of dioecy in flowering plants. Molecular Ecology 26: 1225-1241.

Koike S, Yamaguchi T, Ohmori S, Hayashi T, Yatou O, Yoshida H. 2015. Cleistogamy decreases the effect of high temperature stress at flowering in rice. Plant Production Science 18: 111-117.

Koltunow AM, Grossniklaus U. 2003. Apomixis: a developmental perspective. Annual Review of Plant Biology 54: 547-574.

Kubitzki K, Kurz H. 1984. Synchronized dichogamy and dioecy in Neotropical Lauraceae. Plant Systematics and Evolution 147: 253-266.

Ladd D, Cappuccino N. 2005. A field study of seed dispersal and seedling performance in the invasive exotic vine Vincetoxicum rossicum. Canadian Journal of Botany 83: 1181-1188.

Lakshmanan KK, Ambegaokar KB. 1984. Polyembryony. In: Johri BM. (ed.) Embryology of angiosperms. Berlin, Springer-Verlag. p. 445-474.

Lewis D. 1942. The evolution of sex in flowering plants. Biological Reviews 17: 46-67.

Li J, Newbigin E. 2002. Self-incompatibility in flowering plants: the ribonuclease-based systems. In: O'neill SD, Roberts JA. (eds.) Plant Reproduction. Sheffield, Sheffield Academic Press. p. 257-274.

Li QJ, Kress WJ, Xu ZF, et al. 2002. Mating system and stigmatic behaviour during flowering of Alpinia kwangsiensis (Zingiberaceae). Plant Systematics and Evolution 232: 123-132.

Li QJ, Xu ZF, Kress WJ, et al. 2001. Pollination: flexible style that encourages outcrossing. Nature 410: 432-432.

Lloyd DG. 1975. The maintenance of gynodioecy and androdioecy in angiosperms. Genetica 45: 325-339.

Lloyd DG. 1980. Sexual strategies in plants. New phytologist 86: 69-79.

Lloyd DG. 1992. Self- and Cross-Fertilization in Plants. II. The Selection of Self- Fertilization. International Journal of Plant Sciences 153: 370-380.

Lloyd DG, Schoen DJ. 1992. Self- and cross-fertilization in plants. I. Functional dimensions. International Journal of Plant Sciences 153: 358-369.

Lloyd DG, Webb CJ. 1986. The avoidance of interference between the presentation of pollen and stigmas in angiosperms. I. Dichogamy. New Zealand Journal of Botany 24: 135-162.

Lloyd DG, Webb CJ. 1992. The selection of heterostyly. In: Barrett SCH. (ed.) Evolution and function of heterostyly. Berlin, Springer Verlag. p. 179-208.

Lord EM. 1981. Cleistogamy: a tool for the study of floral morphogenesis, function and evolution. The Botanical Review 47: 421-449.

Luo Y, Widmer A. 2013. Herkogamy and its effects on mating patterns in Arabidopsis thaliana. PLOS ONE 8: e57902. doi: 10.1371/journal. pone.0057902

Luo Z, Zhang D, Renner SS. 2008. Why two kinds of stamens in buzzpollinated flowers? Experimental support for Darwin's division-oflabour hypothesis. Functional Ecology 22: 794-800.

Mable BK, Schierup MH, Charlesworth D. 2003. Estimating the number, frequency, and dominance of S-alleles in a natural population of 
Arabidopsis lyrata (Brassicaceae) with sporophytic control of selfincompatibility. Heredity 90: 422-431.

Małobęcki A, Marcussen T, Bohdanowicz J, Migdałek G, Słomka A, Kuta E. 2016. Cleistogamy and phylogenetic position of Viola uliginosa (Violaceae) re-examined. Botanical Journal of the Linnean Society 182: 180-194.

Mather K. 1950. The genetical architecture of heterosyly in Primula sinensis. Evolution 4: 340-352.

Mayers AM, Lord EM. 1983. Comparative flower development in the cleistogamous species Viola odorata. II. An organographic study. American Journal of Botany 70: 1556-1563.

Mendes-Rodrigues C, Carmo-Oliveira R, Talavera S, Arista M, Ortiz PL, Oliveira PE. 2005. Polyembryony and apomixis in Eriotheca pubescens (Malvaceae-Bombacoideae). Plant Biology 7: 533-540.

Mendes-Rodrigues C, Sampaio DS, Costa ME, et al. 2012. Polyembryony increases embryo and seedling mortality but also enhances seed individual survival in Handroanthus species (Bignoniaceae). Flora 207: 264-274.

Mingxun R. 2010. Stamen movements in hermaphroditic flowers: diversity and adaptive significance. Journal of Plant Ecology (Chinese Version) 34: 867-875.

Mitchell CH, Diggle PK. 2005. The evolution of unisexual flowers: morphological and functional convergence results from diverse developmental transitions. American Journal of Botany 92: 10681076.

Munné-Bosch S. 2015. Sex ratios in dioecious plants in the framework of global change. Environmental and Experimental Botany 109: 99-102.

Naiki A. 2012. Heterostyly and the possibility of its breakdown by polyploidization. Plant Species Biology 27: 3-29.

Nair H, Arditti J. 1991. Resupination in orchids. III. Effects of indoleacetic, naphthaleneacetic and gibberellic acids and benzyladenine on buds and flowers of Aranda Kooi Choo. Lindleyana 6: 154-161.

Naumova TN. 2008. Apomixis and amphimixis in flowering plants. Cytology and Genetics 42: 179-188.

Neal PR, Anderson GJ. 2005. Are 'mating systems' 'breeding systems' of inconsistent and confusing terminology in plant reproductive biology? or is it the other way around? Plant Systematics and Evolution 250: 173-185.

Nettancourt D. 1977. Incompatibility in angiosperms. Berlin Heidelberg New York, Springer.

Nettancourt D. 2001. Incompatibility and incongruity in wild and cultivated plants. Berlin Heidelberg New York, Springer.

Nogler GA. 1984. Gametophytic apomixis. In: Johri BM. (ed.) Embryology of angiosperms. Berlin, Springer. p. 475-518.

Noirot M, Couvet D, Hamon S. 1997. Main role of self-pollination rate on reproductive allocations in pseudogamous apomitics. Theoretical and Applied Genetics 95: 479-483.

Novo RR, Consolaro H, Almeida NM, Castro CC. 2018. Floral biology of the velvetseed Guettarda platypoda DC. (Rubiaceae): Atypical distyly or style dimorphism? Flora 239: 62-70.

Noyes RD. 2007. Apomixis in the Asteraceae: Diamonds in the rough. Functional Plant Science and Biotechnology 1: 207-222.

O’Brien SP, Calder DM. 1989. The breeding biology of Epacris impressa: Is this species heterostylous? Australian Journal of Botany 37: 43-54.

Oliveira PE, Maruyama PK. 2014. Sistemas reprodutivos. In: Rech AR, Agostini K, Oliveira PE, Machado IC. (eds.) Biologia da polinização. Rio de Janeiro, Projeto Cultural. p. 71-92.

Paer C, Saumitou-Laprade P, Vernet P, Billiard S. 2015. The joint evolution and maintenance of self-incompatibility with gynodioecy or androdioecy. Journal of Theoretical Biology 371: 90-101.

Pamela V, Dowrick VP. 1956. Heterostyly and homostyly in Primula obconica. Heredity 10: 219-236.

Pandey KK. 1958. Time of the S allele action. Nature 181: 1220-1221.

Pannell JR, Verdú M. 2006. The evolution of gender specialization from dimorphic hermaphroditism: paths from heterodichogamy to gynodioecy and androdioecy. Evolution 60: 660-673.

Ramírez N. 2005. Plant sexual systems, dichogamy, and herkogamy in the Venezuelan Central Plain. Flora 200: 30-48.
Ramirez N, Brito Y. 1990. Reproductive biology of a tropical palm swamp community in the Venezuelan Llanos. American Journal of Botany 77: 1260-1271.

Rea AC, Nasrallah JB. 2008. Self-incompatibility systems: barriers to self-fertilization in flowering plants. International Journal of Developmental Biology 52: 627-636.

Renner SS. 2001. How common is heterodichogamy? Trends in Ecology \& Evolution 16: 595-597.

Renner SS. 2014. The relative and absolute frequencies of angiosperm sexual systems: dioecy, monoecy, gynodioecy, and an updated online database. American Journal of Botany 101: 1588-1596.

Renner SS, Ricklefs RE. 1995. Dioecy and its correlates in the flowering plants. American Journal of Botany 82: 596-606.

Richards AJ. 1996. Genetic variability in obligate apomicts of the genus Taraxacum. Folia Geobotanica \& Phytotaxonomica 31: 405-414.

Richards AJ. 1997. Plant breeding systems. 2nd. edn. London, Chapman \& Hall.

Richards AJ. 1998. Lethal linkage and its role in the evolution of plant breeding systems. In: Owens SJ, Rudall PJ. (eds.) Reproductive biology in systematics, conservation, and economic botany. Kew, Royal Botanic Gardens. p. 71-83.

Richards AJ. 2003. Apomixis in flowering plants: an overview. Philosophical Transactions of the Royal Society B 358: 1085-1093.

Ruan JC, Silva JAT. 2011. Adaptive significance of floral movement. Critical Reviews in Plant Sciences 30: 293-328.

Ruan CJ, Silva JAT, Qin P. 2010. Style curvature and its adaptive significance in the Malvaceae. Plant Systematics and Evolution 288: 13-23.

Ruiz-Martín J, Santos-Gally R, Escudero M, Midgley JJ, Pérez-Barrales R, Arroyo J. 2018. Style polymorphism in Linum (Linaceae): a case of Mediterranean parallel evolution? Plant Biology 20: 100-111.

Sá T, Furtado MT, Ferrero V, et al. 2016. Floral biology, reciprocal herkogamy and breeding system in four Psychotria species (Rubiaceae) in Brazil. Botanical Journal of the Linnean Society 182: 689-707.

Santos APM, Fracasso CM, Santos ML, Romero R, Sazima M, Oliveira PE. 2012. Reproductive biology and species geographical distribution in the Melastomataceae: a survey based on New World taxa. Annals of Botany 110: 667-679.

Saumitou-Laprade P, Vernet P, Vassiliadis C, et al. 2010. A self-incompatibility system explains high male frequencies in an androdioecious plant. Science 327: 1648-1650.

Sauquet H, Balthazar M, Magallón S, et al. 2017. The ancestral flower of angiosperms and its early diversification. Nature Communications 8: 16047. doi: 10.1038/ncomms 16047

Savidan YH. 2000. Apomixis: genetics and breeding. Plant Breeding Reviews 18: 13-86.

Savidan YH. 2007. Apomixis in higher plants. In: Hörand E, Grossniklaus U, Dijk PJ, Sharbe T. (eds.) Apomixis: evolution, mechanisms and perspectives. Ruggell, Liechtenstein, ARG-Gantner. p. 15-22.

Silvertown J, Charlesworth D. 2001. Introduction to plant population biology. Oxford/ Malden, Blackwell Science.

Silvertown J. 2008. The evolutionary maintenance of sexual reproduction; evidence from ecological distribution of asexual reproduction in clonal plants. International Journal of Plant Sciences 169: 157-168.

Simpson MG. 2006. Plant systematics. Burlington, Elsevier Academic Press.

Soltis D, Soltis P, Endress P, et al. 2018. Phylogeny and evolution of the angiosperms: revised and updated edition. Chicago, University of Chicago Press.

Souza MS, Venturieri GA. 2010. Floral biology of cacauhy (Theobroma speciosum-Malvaceae). Brazilian Archives of Biology and Technology 53: 861-872.

Spalik K. 1991. On evolution of andromonoecy and 'overproduction' of flowers: a resource allocation model. Biological Journal of the Linnean Society 42: 325-336.

Sritongchuay T, Bumrung S, Meesawat U, Mazer S. 2010. Stigma closure and re-opening in Oroxylum indicum (Bignoniaceae): causes and consequences. American Journal of Botany 97: 136-143.

Stebbins GL. 1950. Variation and evolution in plants. New York, Columbia Univesity Press. 


\section{João Custódio Fernandes Cardoso, Matheus Lacerda Viana, Raphael Matias, Marco Túlio Furtado, Ana Paula de Souza Caetano, Hélder Consolaro and Vinícius Lourenço Garcia de Brito}

Suetsugu K. 2014. Gastrodia flexistyloides (Orchidaceae), a new mycoheterotrophic plant with complete cleistogamy from Japan. Phytotaxa 175: 270-274.

Sun S, Gao JY, Liao WJ, Li QJ, Zhang DY. 2007. Adaptive significance of flexistyly in Alpinia blepharocalyx (Zingiberaceae): a hand-pollination experiment. Annals of Botany 99: 661-666.

Takayama S, Isogai A. 2005. Self-incompatibility in plants. Annual Review of Plant Biology 56: 467-89.

Talent N. 2009. Evolution of gametophytic apomixis in flowering plants: an alternative model from Maloid Rosaceae. Theory in Biosciences 128: 121-138.

Tanksley SD, Loaiza-Figueroa F. 1985. Gametophytic self-incompatibility is controlled by a single major locus on chromosome 1 in Lycopersicon peruvianum. Genetics 82: 5093-5096.

Torices R, Mendez M, Gómez JM. 2011. Where do monomorphic sexual systems fit in the evolution of dioecy? Insights from the largest family of angiosperms. New Phytologist 190: 234-248.

Tucker MR, Koltunow AM. 2009. Sexual and asexual (apomictic)seed development in flowering plants: molecular, morphological and evolutionary relationships. Functional Plant Biology 36: 1-15.

Vallejo-Marín M, Barrett SCH. 2009. Modification of flower architecture during early stages in the evolution of self-fertilization. Annals of Botany 103: 951-962.

Vallejo-Marín M, Silva EM, Sargent RD, Barrett SC. 2010. Trait correlates and functional significance of heteranthery in flowering plants. New Phytologist 188: 418-425.

Vallejo-Marín M, Manson JS, Thomson JD, Barrett SCH. 2009. Division of labour within flowers: heteranthery, a floral strategy to reconcile contrasting pollen fates. Journal of Evolutionary Biology 22: 828-839.
Webb CJ, Lloyd DG. 1986. The avoidance of interference between the presentation of pollen and stigmas in angiosperms. II. Herkogamy. New Zealand Journal of Botany 24: 163-178.

Weiblen GD, Oyama RK, Donoghue MJ. 2000. Phylogenetic analysis of dioecy in monocotyledons. The American Naturalist 155: 46-58.

Whitehouse HLK. 1950. Multiple allelomorph incompatibility of pollen and style in the evolution of angiosperms. Annals of Botany 14: 199-216.

Whitton J, Sears CJ, Baack EJ, Sarah PO. 2008. The dynamic nature of apomixis in the angiosperms. International Journal of Plant Sciences 169: 169-182.

Williamson MH, Fitter A. 1996. The characters of successful invaders. Biological Conservation 78: 163-170.

Wolf DE, Takebayashi N. 2004. Pollen limitation and the evolution of androdioecy from dioecy. The American Naturalist 163: 122-137.

Xiao CL, Deng H, Xiang GJ, Luguba KE, Guo YH, Yang CF. 2017. Sequential stamen maturation and movement in a protandrous herb: mechanisms increasing pollination efficiency and reducing sexual interference. AoB Plants 9: plx019. doi: 10.1093/aobpla/plx019

Yampolsky C, Yampolsky H. 1922. Distribution of sex forms in the phanerogamic flora. Bibliotheca Genetica 3: 1-62.

Yang L, Shuangquan H. 2006. Adaptive advantages of gynomonoecious species. Acta Phytotaxonomica Sinica 44: 231-239.

Zhang GF, Xie TP, Du GZ. 2012. Variation in floral sex allocation, female success, and seed predation within racemiform synflorescence in the gynomonoecious Ligularia virgaurea (Asteraceae). Journal of Plant Research 125: 527-538.

Zimmerman JK. 1991. Ecological correlates of labile sex expression in the orchid Catasetum viridiflavum. Ecology 72: 597-608. 